\title{
A global vertical datum defined by the conventional geoid potential and the Earth ellipsoid parameters
}

\author{
Hadi Amin ${ }^{1}$ (D) Lars E. Sjöberg ${ }^{1,2} \cdot$ Mohammad Bagherbandi ${ }^{1,2}$
}

Received: 24 January 2019 / Accepted: 22 August 2019 / Published online: 12 September 2019

(c) The Author(s) 2019

\begin{abstract}
The geoid, according to the classical Gauss-Listing definition, is, among infinite equipotential surfaces of the Earth's gravity field, the equipotential surface that in a least squares sense best fits the undisturbed mean sea level. This equipotential surface, except for its zero-degree harmonic, can be characterized using the Earth's global gravity models (GGM). Although, nowadays, satellite altimetry technique provides the absolute geoid height over oceans that can be used to calibrate the unknown zerodegree harmonic of the gravimetric geoid models, this technique cannot be utilized to estimate the geometric parameters of the mean Earth ellipsoid (MEE). The main objective of this study is to perform a joint estimation of $W_{0}$, which defines the zero datum of vertical coordinates, and the MEE parameters relying on a new approach and on the newest gravity field, mean sea surface and mean dynamic topography models. As our approach utilizes both satellite altimetry observations and a GGM model, we consider different aspects of the input data to evaluate the sensitivity of our estimations to the input data. Unlike previous studies, our results show that it is not sufficient to use only the satellite-component of a quasi-stationary GGM to estimate $W_{0}$. In addition, our results confirm a high sensitivity of the applied approach to the altimetry-based geoid heights, i.e., mean sea surface and mean dynamic topography models. Moreover, as $W_{0}$ should be considered a quasi-stationary parameter, we quantify the effect of time-dependent Earth's gravity field changes as well as the time-dependent sea level changes on the estimation of $W_{0}$. Our computations resulted in the geoid potential $W_{0}=62636848.102 \pm 0.004 \mathrm{~m}^{2} \mathrm{~s}^{-2}$ and the semi-major and minor axes of the MEE, $a=6378137.678 \pm 0.0003 \mathrm{~m}$ and $b=6356752.964 \pm 0.0005 \mathrm{~m}$, which are 0.678 and $0.650 \mathrm{~m}$ larger than those axes of GRS80 reference ellipsoid, respectively. Moreover, a new estimation for the geocentric gravitational constant was obtained as $\mathrm{GM}=(398600460.55 \pm 0.03) \times 10^{6} \mathrm{~m}^{3} \mathrm{~s}^{-2}$.
\end{abstract}

Keywords Geodetic reference system · Geoid potential $W_{0} \cdot$ Global vertical datum $\cdot$ Mean Earth ellipsoid $\cdot$ Reference ellipsoid

\section{Introduction}

From the geopotential point of view, the precise definition and realization of a unified global vertical reference system require the adoption of a global potential value assigned to the zero height level (Sánchez 2007, 2009). According to the classical Gauss-Listing definition, the geoid is the equipotential surface of the Earth's gravity field that in a least squares sense best fits the undisturbed mean sea level (Gauss 1828;

Hadi Amin

hadi.amin@hig.se

1 Faculty of Engineering and Sustainable Development, University of Gävle, 80176 Gävle, Sweden

2 Division of Geodesy and Satellite Positioning, Royal Institute of Technology (KTH), 10044 Stockholm, Sweden
Listing 1873). This definition describes the level surface of the Earth's gravity field that can be assigned as the reference for unifying regional height systems into a global system. Therefore, choosing the geoid as the global vertical datum implies that the datum is defined by the potential $\left(W_{0}\right)$ of this particular level surface of the Earth's gravity field (Sjöberg 2013).

Since the Earth's gravity field undergoes temporal variations, the geoid cannot be considered as a static surface. Furthermore, as Wahr et al. (1998) described in detail, for periods less than several hundred years, temporal changes in the Earth's gravity field are mainly attributed to the movement of water masses within the Earth's relatively thin fluid envelope that can be revealed using space geodetic techniques. Therefore, sea level change and mass redistribution affect the equipotential surfaces in the Earth's gravity 
field. Consequently, as the data have significantly improved and global mean sea level change has increased to about $3.7 \mathrm{~mm} \mathrm{year}^{-1}$ today (Chen et al. 2018), the geopotential at the geoid $\left(W_{0}\right)$ needs to be updated so that it fulfills the Gauss-Listing definition. This implies that, considering the Gauss-Listing definition, the geoid potential $W_{0}$ will generally not be equal to the normal potential $U_{1}$ at the selected reference ellipsoid, e.g., Geodetic Reference System 1980 (Sjöberg 2013).

On the other hand, as Sánchez et al. (2016) reported, a maximum difference of order $-2.6 \mathrm{~m}^{2} \mathrm{~s}^{-2}$ has been noticed in the $W_{0}$ estimations provided since 2005 that corresponds to a height difference of about $27 \mathrm{~cm}$. This level of discrepancy over the short period is mainly due to the differences in the treatment of the input data. Therefore, since the gravity field and mean sea surface (MSS) models have been considerably improved, applying standardized data and new procedures lead to a new estimate of $W_{0}$.

$W_{0}$, as the potential of the geoid, defines the vertical datum of a unified height reference system with respect to the Earth's body. Moreover, as a parameter of the Earth's gravity field, a global estimation of $W_{0}$ is required for the determination of the reference mean Earth ellipsoid (MEE) that is defined as the globally best-fitting ellipsoid to the geoid surface (Heiskanen and Moritz 1967, p. 214). Using observations from space geodetic techniques (namely satellite altimetry, satellite gravimetry and satellite laser ranging), many studies aimed to estimate a global value for $W_{0}$. With the advent of radar altimetry technique in the 1970s, and especially since 1992, different satellite altimetry missions have provided a valuable source of high precision, nearly global records of sea level changes at 10-day intervals. Altimetrybased observations enabled the realization of a global vertical datum of a height system as being the equipotential surface of the Earth's gravity field that in a least squares sense minimizes the difference between mean sea level (MSL) and the Gauss-Listing geoid (called either mean dynamic topography; MDT, or sea surface topography; SST) all over the oceans (Mather 1978). Accordingly, direct method for determining $W_{0}$, discussed in Sect. 2.1, implies a direct integration of the satellite altimetry-derived MDT in combination with the potential achieved from a GGM over all the ocean areas (cf. Sacerdote and Sansó 2004).

Considering different techniques and a variety of datasets, many studies have aimed to estimate a global value for geoid potential, $W_{0}$. Along with defining GRS80 reference ellipsoid, Moritz (2000) equated $W_{0}$ with the normal potential $\left(U_{1}\right)$ at the surface of that new level ellipsoid and reported $W_{0}$ $=62636860.850 \mathrm{~m}^{2} \mathrm{~s}^{-2}$. Rapp et al. (1991) and Rapp (1995) followed the same approach $\left(W_{0}=U_{1}\right)$ and concentrated on the best-fitting ellipsoid for the TOPEX/POSEIDON MSS and quantified $W_{0}=62636858.546 \mathrm{~m}^{2} \mathrm{~s}^{-2}$ and $W_{0}=$ $62636856.88 \pm 1.0 \mathrm{~m}^{2} \mathrm{~s}^{-2}$, respectively. In a more recent study, assuming that $W_{0}=U_{1}$, Dayoub et al. (2012) considered the best-fitting ellipsoid for the DNSC08 MSS and estimated $W_{0}$ based on two different scenarios, namely with and without taking into account a MDT model in their computations (as geoid = MSS - MDT, disregarding the MDT assumes that there is no discrepancy between the geoid and MSS). Reporting $W_{0}$ values as $62636854.18 \pm 0.01$ and $62636854.19 \pm 0.01 \mathrm{~m}^{2} \mathrm{~s}^{-2}$ for two scenarios, respectively, they concluded that on using the largest latitudinal extents of MSS model, it is not necessary to utilize a MDT model.

After the possibility of estimating dynamic ocean topography using satellite altimetry observations and a pre-defined geoid model, many studies aimed to estimate $W_{0}$ in a different way than equating with $U_{1}$. Burša et al. (1992, 1997, 1998a, b, 1999, 2001, 2002, 2007a, b), Nesvorný and Šíma (1994), Sánchez (2007) and Dayoub et al. (2012) aimed at estimating the global value for $W_{0}$ corresponding to the level surface that minimizes the square sum of the dynamic ocean topography estimated over all the ocean areas. Accordingly, based on different MSS models, various GGMs to define a priori geoid, considering or not considering a MDT model to define mean sea surface, different MDT models as well as different time periods, a range of $W_{0}$ values varying between $62636853.31 \pm 0.02 \mathrm{~m}^{2} \mathrm{~s}^{-2}$ (Dayoub et al. 2012) and $62636857.5 \pm 1.0 \mathrm{~m}^{2} \mathrm{~s}^{-2}$ (Nesvorný and Šíma 1994) have been reported. In these studies, Burša et al. (1992, 1998b, 2002, 2007a, b), Nesvorný and Šíma (1994) and Sánchez (2007) did not take into account a MDT model (assuming that the geoid is equivalent to MSS), whereas Burša et al. (1997, 1998a) considered mean sea surface as a difference between a MSS model and a MDT model. However, Dayoub et al. (2012) examined both strategies to quantify the effect of a MDT model on the estimation of $W_{0}$. They found that while employing MSS values over a latitudinal band coverage from $70^{\circ} \mathrm{N}$ to $70^{\circ} \mathrm{S}$, MDT has near-zero effect on the $W_{0}$ estimation, and an unbiased value for $W_{0}$ can be achieved without using a MDT model.

Concentrating on the dynamic ocean topography achieved from satellite altimetry observations and a gravity model, Burša et al. (1997, 1998a, 1999, 2001, 2007a, b) considered the sensitivity of estimated $W_{0}$ to the tidal reference system of the Earth's gravity field. By a closer look at the Earth's gravity field in terms of the various wavelengths, they found that their estimate $W_{0}=62636856.0 \pm 0.5 \mathrm{~m}^{2} \mathrm{~s}^{-2}$ is relatively independent of the spherical harmonics of degrees larger than 120. As the harmonic coefficients of a static gravity field have signatures of periodic, quasi-secular and secular nature (Moore et al. 2006), Burša et al. (1999, 2007a) also investigated the secular variations in $W_{0}$. Sánchez (2007) investigated the global determination of the geoid potential and its sensitivity to global gravity field models. Considering four different GGMs, Sánchez (2007) reported that the estimated $W_{0}=62636853.4 \mathrm{~m}^{2} \mathrm{~s}^{-2}$ is insensitive to the 
choice of GGM. In contrast, she found that the latitudinal coverage of the MSS plays a significant role. In a comparative study, Dayoub et al. (2012) aimed to estimate $W_{0}$ and its temporal rate by utilizing altimetry-derived MSS models and an independent MDT model, and considering two different approaches: (1) by means of a GGM and (2) within normal gravity field space as the geopotential value of the best-fitting reference ellipsoid. They revealed that the uncertainty in $W_{0}$ is relatively insensitive to the choice of methodology, GGM and MSS data coverage, and it is mainly attributed to the selected MDT. Their estimated $W_{0}=62636854.2 \pm 0.2 \mathrm{~m}^{2}$ $\mathrm{s}^{-2}$ differs by $0.8 \mathrm{~m}^{2} \mathrm{~s}^{-2}$ from the one estimated by Sánchez (2007). Reporting $\mathrm{d} W_{0} / \mathrm{dt}=(-2.70 \pm 0.03) \times 10^{-2} \mathrm{~m}^{2} \mathrm{~s}^{-2}$ year $^{-1}$, which corresponds to a global mean sea level rise of $2.9 \mathrm{~mm}$ year $^{-1}$, they argued that, at a sub-decadal interval, the variations of $W_{0}$ over time arise mainly from sea level change.

Čunderlík and Mikula (2009) estimated $W_{0}$ as a numerical result of applying the boundary element method to the linear altimetry-gravimetry boundary value problem. They utilized the collocation technique with linear basis functions for discretization of boundary element method over both land and ocean areas. Within land areas, they used geocentric positions, derived from a global topography model along with a GGM, to model the fixed Earth's surface. In addition, over oceans, altimetry-based MSS models the geometry of fixed Earth's surface. They also included surface gravity disturbances at collocation points using a GGM. Consequently, a perturbation of the Dirichlet boundary condition is applied as a difference between the normal gravity potential at the surface of the reference ellipsoid and the gravity potential of geoid, $\delta W=W_{0}-U_{1}$. Accordingly, they found $W_{0}=$ $62636857.95 \mathrm{~m}^{2} \mathrm{~s}^{-2}$, and a difference of $\delta W=-2.896 \mathrm{~m}^{2}$ $\mathrm{s}^{-2}$ was estimated from the normal potential on the reference ellipsoid.

Relying on the most recent released GGMs as well as MSS models and utilizing standardized data and procedures, Sánchez et al. (2016) determined a new $W_{0}$ estimate based on the scalar-free geodetic boundary value problem. In agreement with previous studies (e.g., Sánchez 2007; Burša et al. 2007a; Dayoub et al. 2012), they concluded that the estimated $W_{0}$ is independent of the harmonics of degrees $n>200$ of a static GGM, and it can be computed using satelliteonly component of harmonics with a GGM. Dayoub et al. (2012) explained that the insensitivity of the estimated $W_{0}$ to the higher degree harmonics is due to the relative smoothness of the geopotential (Dayoub et al. 2012, Eq. 1) as a function of latitude and longitude. Moreover, in that context, Sánchez et al. (2016) examined eight different GGMs and concluded that, except for the EGM96, all the models result practically in the same estimate of $W_{0}$ (a maximum difference of $0.006 \mathrm{~m}^{2} \mathrm{~s}^{-2}$ has been reported). Considering the GRACE $^{1}$-based GGM series to study influence of the time-dependent gravity field changes in $W_{0}$, the linear trend of $W_{0}$ variations has been estimated to be $-6.617 \times 10^{-4}$ $\mathrm{m}^{2} \mathrm{~s}^{-2}$ year $^{-1}$ (that corresponds to a displacement of about $+1.3 \mathrm{~mm}$ in 20 years in the level surface). They discussed that this trend is much smaller than the error in the estimation of $W_{0}$ and can, therefore, be neglected. Sánchez et al. (2016) also discussed if the empirical estimation of $W_{0}$ is influenced by the selection of MSS and MDT models, timedependent sea surface changes and the tide system. Reporting the dependency of the estimated $W_{0}$ on the selected MSS, they concluded that the empirical estimation of $W_{0}$ should be based on the total area covered by the MSS model. Furthermore, they reported that it is not essential to utilize a MDT model when all the ocean areas covered by the satellite altimetry are included in the estimation of $W_{0}$. In terms of the sensitivity to time-dependent sea surface changes, they utilized yearly MSS models and concluded that an estimate of $\mathrm{d} W_{0} / \mathrm{d} t$ is necessary as the Gauss-Listing definition must be satisfied at any time. They also considered differences between $W_{0}$ values estimated based on different tide systems and reported that the input data for the computation of $W_{0}$ (GGM and MSS models) should be given in the same tide system.

As a different method from the global approach, Ardalan et al. (2002) estimated $W_{0}$ to $62636855.75 \pm 0.21 \mathrm{~m}^{2} \mathrm{~s}^{-2}$ based on an ellipsoidal harmonic expansion of the external gravity field at the stationary GPS stations around the Baltic Sea. They also used regional tide gauge and GPS observations to study the secular variation in $W_{0}$.

The aim of this study is to examine a new method that simultaneously estimates the geoid potential and the geometrical parameters of the MEE. In this way, we will arrive at the best fits of geoid potential and geometric parameters of the MEE that match each other according to the definitions of the geoid and the MEE. (See Eq. 16). Accordingly, the paper is outlined as follows: Sect. 2 presents the methodology for determining the geoid potential. Section 2.1 presents direct method that has been published and tested in the geodetic literature, included as a background for understanding Sect. 2.2, which is the method, first published by Sjöberg (2013), to be numerically applied in this analysis for the first time. Section 3 discusses in detail all the input data employed throughout this study. Further, we summarize the results and discuss the achievements in Sect. 4. Finally, Sect. 5 presents the conclusions.

\footnotetext{
${ }^{1}$ GRACE: Gravity Recovery and Climate Experiment, http://www.csr. utexas.edu/grace/.
} 


\section{Methodology for the estimation of $W_{0}$}

The original Stokes' formula (Stokes 1849) yields the geoid height $(N)$ as follows:

$N=\frac{R}{4 \pi \gamma} \iint_{\sigma}\left(\sum_{n=2}^{\infty} \frac{2 n+1}{n-1} P_{n}(\cos \psi)\right) \Delta g \mathrm{~d} \sigma$,

where $\gamma$ is the normal gravity on the reference ellipsoid along its normal through the computation point, $R$ is the radius of the mean Earth sphere, $P_{n}(\cos \psi)$ is the Legendre's polynomial of degree $n, \psi$ is the geocentric angle between the computation point and the running point of integration, $\Delta g$ is the gravity anomaly and $\sigma$ is the unit sphere. This equation lacks the zero-degree term $N_{0}$ (Martinec 1998), implying that the geoid cannot be determined in an absolute sense. The classical way to estimate this term (corresponding to $W_{0}$ ) was by determining at least one distance at (or reduced to) sea level and comparing it with the distance along the reference ellipsoid. In this way, $N_{0}$ and thereby $W_{0}$ can be determined, by dividing $N_{0}$ by normal gravity (Heiskanen and Moritz 1967, p. 103-104).

The following sections discuss two approaches for determining $W_{0}$. The direct method in Sect. 2.1 has been already published and numerically applied in the literature. Section 2.2 presents our approach, originally presented by Sjöberg (2013), which we will later use for our numerical study. See also Sjöberg and Bagherbandi (2017, Sect. 7.4).

\subsection{Direct determination of $W_{0}$ from satellite altimetry and a GGM}

Using spherical harmonic coefficients of a GGM and by neglecting the atmosphere, one can use the following equation to estimate the Earth's gravity potential, $\tilde{W}$, outside the topographic masses (Torge 1989, p. 70 and 72):

$$
\begin{aligned}
\tilde{W}(r, \theta, \lambda)= & \frac{\mathrm{GM}_{1}}{r}\left[1+\sum_{n=2}^{n_{\max }}\left(\frac{R}{r}\right)^{n+1} \sum_{m=-n}^{n} A_{\mathrm{nm}} Y_{\mathrm{nm}}(\theta, \lambda)\right] \\
& +\phi(r, \theta, \lambda),
\end{aligned}
$$

where $(r, \theta, \lambda)$ are the geocentric radius, spherical co-latitude and longitude of the computational point, $\mathrm{GM}_{1}$ is an adopted value for the geocentric gravitational constant and $\phi$ is the Earth's rotational potential. Each spectral potential component $A_{n m}$ is determined from a global set of gravity-related data by harmonic analysis up to the chosen degree and order $n_{\max }$ at the reference radius $R$, and $Y_{\mathrm{nm}}(\theta, \lambda)$ is the surface spherical harmonic of degree $n$ and order $m$. In this equation, the zero-degree harmonic is equal to the gravity potential on the surface of the defined reference ellipsoid, which is only preliminary. It can be seen that we solve this problem in our approach. The absence of first-degree coefficients in Eq. (2) implies that the origin of the coordinate system is selected at the Earth's gravity center. Similarly, the constant normal potential $U_{1}$ on the surface of a reference ellipsoid with mass $M_{1}$ can also be represented as a harmonic series of the gravitational potential plus the centrifugal potential (Sjöberg and Bagherbandi 2017, p. 222):

$$
\begin{aligned}
U_{1}(r, \theta, \lambda)= & \frac{\mathrm{GM}_{1}}{r}\left[1+\sum_{n=2}^{n_{\max }}\left(\frac{R}{r}\right)^{n} \sum_{m=-n}^{n} B_{\mathrm{nm}} Y_{\mathrm{nm}}(\theta, \lambda)\right] \\
& +\phi(r, \theta, \lambda),
\end{aligned}
$$

where $B_{\mathrm{nm}}$ is the potential coefficient of degree $n$ and order $m$ from a global gravity field model. Then, the disturbing potential, $T^{\mathrm{GGM}}$, can be achieved as $T^{\mathrm{GGM}}=\tilde{W}(r, \theta, \lambda)-$ $U_{1}(r, \theta, \lambda)$.

Using Eq. (2), one can directly estimate the geoid potential, $W_{0}$, as the potential at the radius vector $r_{g}$ of the geoid (cf. Dayoub et al. 2012; Sjöberg and Bagherbandi 2017):

$\hat{W}_{g}=\hat{W}_{0}=\hat{W}\left(r_{g}, \theta, \lambda\right)$,

where by defining $r_{1}(\theta)$ as the geocentric radius vector of the defined reference ellipsoid and $N(\theta, \lambda)$ as the related geoid height:

$r_{g}=r_{g}(\theta, \lambda)=r_{1}(\theta)+N(\theta, \lambda)$.

Within ocean areas, $N$ can be geometrically estimated as the difference between satellite altimetry-derived MSS and MDT in which the latter can be derived either by oceanographic techniques or from satellite altimetry and a preliminary geoid model.

As an alternative method, Bruns' formula can be used to estimate the normal potential at the geoid surface; $U_{g}$ (Heiskanen and Moritz 1967, p. 84):

$T_{g}=W_{0}-U_{g}=W_{0}-\left(U_{1}-\gamma_{1} N\right)$,

where $\gamma_{1}$ is the normal gravity on the surface of the reference ellipsoid. Consequently (see also Sacerdote and Sansó 2004):

$W_{0}=U_{1}-\gamma_{1} N+T_{g}$.

Considering the negligibility of using $r_{1}(\theta)$ instead of $r_{g}$, one can represent $T_{g}$ by $T^{\mathrm{GGM}}=T^{\mathrm{GGM}}\left(r_{1}(\theta), \theta, \lambda\right)$. Therefore, by denoting $\Delta W_{0}=W_{0}-U_{1}$, Eq. (7) leads to:

$N=\frac{T^{\mathrm{GGM}}}{\gamma_{1}}-\frac{\Delta W_{0}}{\gamma_{1}}$. 
Utilizing spherical harmonic coefficients of a GGM, one can write Bruns' formula (Bruns 1878) to determine $N^{\mathrm{GGM}}$ as:

$N^{\mathrm{GGM}}=\frac{T^{\mathrm{GGM}}}{\gamma_{1}}$,

which reveals that comparing with Eq. (8), GGM-derived geoid height lacks the unknown correction $-\Delta W_{0} / \gamma_{1}$.

It should be noted that, as $T_{g}$ is the disturbing potential inside the topographic mass, therefore, its estimation over the continents and consequently the determination of $N^{\mathrm{GGM}}$, Eq. (9), requires the analytical downward continuation error or topographic bias of $T_{g}^{\mathrm{GGM}}$ (Sjöberg 1977, 2007; Martinec 1998, Sects. 7.3-7.4; Ågren 2004; Sjöberg and Bagherbandi 2017).

Taking the advantage of satellite altimetry in determining MSS, as well as using a GGM to estimate disturbing potential on the surface of the undisturbed sea level (corrected for MDT), one can compute $W_{0}$ as the first-order Taylor expansion as follows (Sacerdote and Sansó 2004):

$W_{0}=U_{g}+T_{g}=U_{1}-\gamma h_{g}+T_{g}^{\mathrm{GGM}}$,

where $h_{g}=\mathrm{MSL}-\mathrm{MDT}=N^{\text {alt }}$ is the satellite altimetryderived geoid height. Therefore, taking the mean value of the point-wise estimates for $W_{0}$ over the marine areas $\left(\sigma_{1}\right)$ yields (Sacerdote and Sansó 2004):

$\hat{W}_{0}=U_{1}+\frac{\iint_{\sigma_{1}}\left[\frac{T_{Q}^{\mathrm{GGM}}-\gamma h_{Q}}{\bar{\gamma}_{Q}^{2}}\right] \mathrm{d} \sigma}{\iint_{\sigma_{1}}\left[\frac{1}{\bar{\gamma}_{Q}^{2}}\right] \mathrm{d} \sigma}$,

where $Q$ denotes a surface point and $\bar{\gamma}_{Q}$ is the mean normal gravity along the normal height at $Q$. This method integrates only over oceans and relies on a priori fixed reference ellipsoid that differs in both potential and geometric shape.

Over the continents, one can rewrite Eq. (10) as follows:

$W_{0}=U_{1}-\gamma N^{\mathrm{GNSS} / \text { leveling }}+T_{g}^{\mathrm{GGM}}$,

where $T_{g}^{\mathrm{GGM}}$ needs the topographic correction. As Stokes' formula does not allow external masses to the sphere of integration, the effect of these topographic masses is usually removed from the gravity anomaly prior to Stokes' integration. The topographic correction for potential is presented as (Sjöberg and Bagherbandi 2017, p. 159):

bias $=2 \pi G \rho\left(H^{2}+\frac{2 H^{3}}{3 R}\right)$, where $G$ is the gravitational constant of the Earth, $\rho$ is the standard topographic density (here is assumed to be constant) and $H$ is the topographic height.

\subsection{Our approach: joint determination of $W_{0}$ and the mean Earth ellipsoid parameters using least squares adjustment}

Considering the mean angular velocity of the Earth's daily rotation $(\omega)$ as a known parameter, this approach uses the satellite altimetry and GGM-derived geoid heights in a joint adjustment procedure to estimate both the dimensions of MEE and $W_{0}$.

For the MEE with semi-major axis $a$ and eccentricity $e$, where $\beta$ is the reduced latitude, radius vector of a point on the surface of this MEE is given by:

$r_{E}(\beta)=a \sqrt{1-e^{2} \sin ^{2} \beta}$.

Similarly, for a preliminary reference ellipsoid with geometric parameters $a_{1}$ and $e_{1}$, the radius vector of a point on the surface of this reference ellipsoid can be written as $r_{1}(\beta)=a_{1} \sqrt{1-e_{1}^{2} \sin ^{2} \beta}$.

According to the definition of MEE (Heiskanen and Moritz 1967), as this ellipsoid is the globally best-fitting ellipsoid to the geoid surface, the axes are such that the global mean square of the difference between the radius vector of the geoid surface (estimated by $r_{1}(\beta)+N$ ) and the radius vector $r_{E}(a, e, \beta)$ is a minimum (Sjöberg 2013; Sjöberg and Bagherbandi 2017, Sect. 7.4.3):

$J=\frac{1}{4 \pi} \iint_{\sigma}\left[r_{1}(\beta)+N-r_{E}(a, e, \beta)\right]^{2} \mathrm{~d} \sigma=\min .(a, e)$,

where $\sigma$ is the unit sphere. Note that $r_{1}(\beta)$ is the radius vector of the reference ellipsoid related to geoid estimate $N$ and $r_{E}(a, e, \beta)$ is the radius vector of a MEE that should be optimized.

Introducing $\mathrm{U}_{0}$ as the normal potential of the MEE, one can find this potential as the best choice of $W_{0}$ (e.g., Heiskanen and Moritz 1967):

$W_{0}=U_{0}=\frac{\mathrm{GM}}{a e} \arcsin (e)+\frac{\omega^{2} a^{2}}{3}$,

where GM is the geocentric gravitational constant. By minimizing the target function $J$ in Eq. (15), the ellipsoidal parameters $a$ and $e$ of the MEE will be fixed, which can be used in Eq. (16) to compute the geopotential value at the geoid, i.e., $W_{0}$.

As Sjöberg (2013) and Sjöberg and Bagherbandi (2017) discussed, a problem in using this approach in the estimation 
of $W_{0}$ is that the uncertainty in GM contributes to about $20 \%$ of the uncertainty in $W_{0}$. Groten (2004) reported that the standard error in GM amounting to about $0.8 \mathrm{~m}^{3} \mathrm{~s}^{-2}$ corresponds to the uncertainties in $W_{0}$ and geoid height of about $0.1 \mathrm{~m}^{2} \mathrm{~s}^{-2}$ and $1 \mathrm{~cm}$, respectively, where the presentday uncertainty in $W_{0}$ is about $0.5 \mathrm{~m}^{2} \mathrm{~s}^{-2}$ (e.g., Sánchez 2012).

Moreover, optimizing the target function $J$ implies that we need the absolute geoid height over a global scale, but the geoid height is only relatively well known, such as those estimated by GGMs. Considering this assumption that the MDT is accurately available (with a global mean error of about $2 \mathrm{~cm}$ based on the DTU15MDT model; ftp://ftp.space. dtu.dk/pub/DTU15), one can use satellite altimetry observations to estimate the absolute geoid height over oceans. However, as the target function in Eq. (15) needs to be optimized globally, using only satellite altimetry-derived geoid height leads to the estimation of ellipsoidal parameters and $W_{0}$ within ocean areas only. Considering the level of agreement between satellite altimetry-based geoid surface and that one achieved by the EGM2008 in coastal areas, Dayoub et al. (2012) directly utilized a GGM-based geoid surface over continents to estimate $W_{0}$ using the above approach. But, as stated above, a GGM-based geoid height lacks the unknown correction $-\Delta W_{0} / \gamma_{1}$. Therefore, one need to estimate $a, e$ and $-\Delta W_{0} / \gamma_{1}$ in a combined adjustment to be able to use a GGM-derived geoid surface over the continents.

\subsubsection{The combined adjustment approach}

As in reality, the estimated geoid surface is not continuous and known all over the Earth; we suggest using satellite altimetry technique over oceans and a GGM within the continents to estimate geoid heights. Therefore, this implies that the target function $J$ must be augmented by the extra unknown $x=-\Delta W_{0}=U_{1}-W_{0}$. If we assume that both $N^{\text {alt }}$ and $N^{\mathrm{GGM}}$ are relative to the same reference ellipsoid with parameters $a_{1}, e_{1}$ and $r_{1}(\beta)$, then the target function presented by Eq. (15) can be augmented to (see "Appendix 1 " for more details):

$I=p I_{1}(a, e)+(1-p) I_{2}(x, a, e)+I_{3}(x, a, e)=\min (x, a, e)$,

where

$$
\begin{aligned}
& I_{1}(a, e)=\iint_{\sigma_{1}}\left[N^{\text {alt }}+r_{1}(\beta)-r_{E}(a, e, \beta)\right]^{2} \mathrm{~d} \sigma \\
& I_{2}(x, a, e)=\iint_{\sigma_{1}}\left[\frac{x}{\gamma_{1}}+N^{\mathrm{GGM}}+r_{1}(\beta)-r_{E}(a, e, \beta)\right]^{2} \mathrm{~d} \sigma
\end{aligned}
$$

$I_{3}(x, a, e)=\iint_{\sigma_{2}}\left[\frac{x}{\gamma_{1}}+N^{\mathrm{GGM}}+r_{1}(\beta)-r_{E}(a, e, \beta)\right]^{2} \mathrm{~d} \sigma$.

$\sigma_{1}$ and $\sigma_{2}$ represent ocean-covered and land-covered parts of the unit sphere, respectively, and the weight coefficient $0 \leq p \leq 1$ determines how the $N^{\mathrm{GGM}}$ and $N^{\text {alt }}$ over oceans contribute to the optimization of the target function I. Accordingly, the choice of $p$ could be based on the a priori variances $\kappa_{1}^{2}$ and $\kappa_{2}^{2}$ of the satellite altimetry and GGMderived geoid heights, respectively, yielding

$p=\frac{\kappa_{2}^{2}}{\kappa_{1}^{2}+\kappa_{2}^{2}}$.

Considering the case with $p=0$ implies that, over oceans, only GGM-derived geoid heights contribute to the estimation of the unknowns and satellite altimetry does not play any role in optimizing the target function, i.e., the target function $I$ would be $I_{2}(x, a, e)+I_{3}(x, a, e)$. Sjöberg (2013) pointed out that in this case, the solution is singular and the equation system given by Eqs. (17) and (18) has no solution.

The target function $I$ is minimized by the following conditions

$\frac{\partial I}{\partial x}=0, \quad \frac{\partial I}{\partial a}=0$ and $\frac{\partial I}{\partial e}=0$,

and from these three equations, the solutions for $x, a$ and $e$ can be obtained. The practical solution of this system of equations by iteration is provided in "Appendix 2."

From the above solutions, the geoid potential is obtained as follows:

$\hat{W}_{0}=U_{1}-\hat{x}$

where $\hat{x}$ is the estimated value for the unknown $x$ and $U_{1}$ is the a priori ellipsoidal normal potential. In addition, assuming $W_{0}=U_{0}$ and inserting the estimated $a$ and $e$ into Eq. (16), a new estimate for GM can be obtained by:

$\begin{aligned} \widehat{\mathrm{GM}} & =\left(\hat{W}_{0}-\frac{\hat{a}^{2} \omega^{2}}{3}\right) \frac{\hat{a} \hat{e}}{\arcsin (\hat{e})} \\ & \approx\left(\hat{W}_{0}-\frac{\hat{a}^{2} \omega^{2}}{3}\right) \hat{a}\left(1-\frac{\hat{e}^{2}}{6}\right) .\end{aligned}$

\section{Input data}

Since in this study, the sensitivity of our approach to the different dataset is considered, several models for each group of 
input data have been utilized. The input data for an empirical estimation of $W_{0}$ based on the system of Eqs. (20) are:

\subsection{Global gravity model (GGM)}

Based on the data processing methodology employed to estimate the spherical harmonic coefficients (SHC) as well as the input data utilized for the computations, a wide range of static GGMs have been released, which can be classified into two general categories: GGMs prior to the satellite gravity missions and GGMs based on the satellite gravimetry observations. Terrestrial gravity data, satellite laser ranging (SLR) observations, data from satellite gravity missions (CHAMP, ${ }^{2}$ $\mathrm{GOCE}^{3}$ and GRACE) and different combinations thereof are used nowadays for the computation of the SHCs of the Earth's gravity field. One can find some examples of the GGMs classified based on the input data in Sánchez et al. (2016).

For the purpose of this study to estimate $W_{0}$ and evaluate its sensitivity to the GGMs, we consider those GGMs that provide the maximum possible spectral resolution of the Earth's gravity field (corresponding to the maximum degree and order of the SHCs). Moreover, in terms of accuracy and the number of observations, GGMs based on the most recently released satellite gravity observations provide higher reliability. Therefore, in this study, six GGMs were used, namely EGM2008 (Pavlis et al. 2007, 2012, 2013), SGG-UGM-1 (Liang et al. 2018), EIGEN-6C4 (Förste et al. 2014), GOCO05c (Fecher et al. 2015), EIGEN-6C3stat (Förste et al. 2012) and XGM2016 (Pail et al. 2017). The International Earth Rotation and Reference Systems' Service (IERS) recommend the model EGM2008, a model based on a combination of satellite data with terrestrial gravimetry observations, as the conventional GGM (Sánchez et al. 2016). For more information about the input data, tide system and the maximum degree $n$ /order $m$ of each used GGM, one can refer to the corresponding reference. All the static GGMs are available through the http://icgem.gfz-potsdam.de/home/ (International Centre for Global Earth Models (ICGEM) at GFZ).

In this study, in addition to using the quasi-stationary GGMs for the estimation of $W_{0}$, we utilized GRACE monthly observations to study influence of the time-dependent Earth's gravity field changes in $W_{0}$. GRACE monthly solutions provide the Earth's gravity field in terms of monthly normalized SHCs. For this purpose, the monthly GFZ Release-05a GRACE Level-2 data products (Dahle et al. 2012; Dahle 2017) have been used (the dataset can be accessed with FTP: ftp://podaac-ftp.jpl.nasa.gov/allData/grace/L2/GFZ/RL05).

\footnotetext{
$\overline{2}$ CHAMP: Challenging Minisatellite Payload, http://op.gfz-potsdam. de/champ/.

3 GOCE: Gravity field and steady-state Ocean Circulation Explorer, http://www.esa.int/SPECIALS/GOCE/index.html.
}

Table 1 Major specifications of the mean sea surface models employed in this study

\begin{tabular}{lll}
\hline & MSS_CNES_CLS2015 & DTU18MSS \\
\hline Spatial coverage & Global $\left(84^{\circ} \mathrm{N}-80^{\circ} \mathrm{S}\right)$ & Global $\left(90^{\circ} \mathrm{N}-90^{\circ} \mathrm{S}\right)$ \\
Spatial resolution & $\begin{array}{c}1 / 60^{\circ} \times 1 / 60^{\circ}(1 \mathrm{~min}) \\
\text { regular grid } \\
\end{array}$ & $1 / 60^{\circ} \times 1 / 60^{\circ}(1 \mathrm{~min})$ \\
& $(\sim 1.8 \mathrm{~km} / \mathrm{eq})$ & \\
Reference period & $1993.1-2013.0$ & $1993.1-2013.0$ \\
& $(20$ years $)$ & $(20$ years $)$ \\
Reference ellipsoid & Topex/Poseidon & Topex/Poseidon \\
Dataset & Mean profile: & Mean profile: \\
& TOPEX/POSEIDON, & TOPEX/POSEIDON, \\
& ERS-2, GFO, & ERS-1, ERS-2, \\
& Jason-1, Jason-2, & Jason-1, Jason-2, \\
& ENVISAT & N1, SA \\
& Geodetic mission: & Geodetic mission: \\
& ERS-1, Jason-1 and & SA, Jason-1 and \\
& CryoSat-2 & CryoSat-2 \\
\hline
\end{tabular}

\subsection{Mean sea surface (MSS) models}

Mean sea surface models provide information about the ellipsoidal height of the sea surface as an average of the heights, derived from a standardized multi-mission crosscalibration of several altimeters, over a certain epoch. Therefore, depending on the datasets employed in the averaging as well as the averaging strategies, mean sea surface heights vary from one MSS model to another. To quantify the dependence of $W_{0}$ on the MSS model, we utilized two different MSS models, namely MSS_CNES_CLS2015 (Schaeffer et al. 2016) and DTU18MSS (Andersen et al. 2018a). Table 1 summarizes the major specifications of these two models.

MSS_CNES_CLS2015 has been determined using a local least squares collocation technique that provides an estimation of calibrated error. The model has been computed based on satellite altimetry data (mean profiles, geodetic mission and sea level anomaly) using a 20-year (1993-2012) of TOPEX/POSEIDON, ERS-2, GFO, JASON-1, JASON2, ENVISAT mean profile and data of the ERS-1, Jason-1 and CryoSat-2 geodetic phase. The surface has been estimated globally on a $1^{\prime}(1 \% 60)$ spatial grid between $80^{\circ} \mathrm{S}$ and $84^{\circ} \mathrm{N}$. Comparing with the MSS_CNES_CLS2011, various important components have been improved over the 2011 model processing. For instance, more than 100 million data points have been integrated in the MSS_CNES_CLS2015 version that is three times more than what was used for the 2011 version. Moreover, particular attention was paid to the homogeneity of the ocean content of this MSS, and specific processing was also carried out on data from geodetic missions. For instance, CryoSat-2, Jason-1 GM and ERS-1 GM data were corrected from oceanic variability using results of optimal analysis of sea level anomalies (SLA). In addition, from the accuracy point of view, MSS_CNES_CLS2015 with 
an average error of $1.4 \mathrm{~cm}(\mathrm{Std}=1.3 \mathrm{~cm})$ provides a considerable improvement comparing with MSS_CNES_CLS2011 in which the average error is $1.9 \mathrm{~cm}$ with a standard uncertainty of $2.1 \mathrm{~cm}$ (Schaeffer et al. 2016). A drastic improvement of the shortest wavelengths, a better correction of the oceanic variability, a reduced degradation of SLA near the coast, globally, a strong reduction of errors when computing SLA and more homogeneity of accuracy compared to the former versions are the key points of the new MSS model MSS_CNES_CLS2015 (Schaeffer et al. 2016). One can find a detailed discussion on the MSS_CNES_CLS2015 model and its comparison with the other MSS models in Pujol et al. (2018). The data can be downloaded through Archiving, Validation and Interpretation of Satellite Oceanographic (AVISO; https://www.aviso. altimetry.fr/en/data/products/auxiliary-products/mss.html).

DTU18MSS has also been estimated using 20 years of satellite altimetry data over 1993-2012. The model is available on a 1-min and a 2-min spatial resolution over $90^{\circ} \mathrm{S}-90^{\circ} \mathrm{N}$ latitudinal coverage through the Web site of the national space institute in the Technical University of Denmark, DTU space (ftp://ftp.space.dtu.dk/pub/DTU18). In comparison with the former versions, a new processing methodology along with a new version of ocean tide model (FES2014) has been performed underpinning DTU18MSS. A four-step improvement scheme has been implemented to update DTU15MSS to DTU18MSS: (1) the use of new Arctic and Antarctic dataset, (2) long wavelength correction T/P, Jason-1 and Jason-2 mean profiles, (3) coastal zone update using Sentinel-3A and T/P, Jason-1 and Jason-2 profiles and (4) removing geodetic mission ocean variability in interpolation (Andersen et al. 2018b).

As any MSS model is estimated using sea surface heights averaged over a certain time epoch, time-dependent factors that affect the sea surface heights underpinning the model must be removed. Therefore, it is assumed that the modelderived sea surface heights are static over the averaging period. Accordingly, we also concentrate on the use of a series of monthly and yearly mean sea surface estimates in order to evaluate influence of time-dependent sea surface changes in $W_{0}$. The monthly SLA series were provided by AVISO.

\subsection{Mean dynamic topography (MDT) models}

The other variable contributing to the system of Eqs. (20) is the MDT, which is used together with an altimetry-derived MSS model (by removing the MDT from the MSS) to define points on the geoid over oceans. Generally, based on the processing methodology and the input data, MDT models can be classified into two categories: geodetic and oceanographic MDT. The geodetic MDT is defined as the difference between sea surface heights (derived from satellite altimetry) and geoid heights (derived from a pre-defined geoid model). Therefore, if one uses a geodetic MDT model in the estimation of $W_{0}$, it means that a pre-given geoid is already contributing. In such cases, if that geoid is already assigned with a geopotential value, it leads to a futile estimation of $W_{0}$. Therefore, it is not reasonable to utilize a geodetic MDT model for the estimation of $W_{0}$. On the contrary, the oceanographic MDT models are not computed directly as the difference between a satellite altimetry-based sea surface model and a geoid model but achieved by solving the equations describing motion of the water masses; i.e., they are based on solution of the evolving ocean state within a global circulation model over a specific time period. The main assumption in solving the equations of motion is that there is a hydrostatic balance of sea water with respect to a reference level of no-motion that coincides with an equipotential surface. Since the no-motion reference surface does not exactly coincide with the geoid as the reference level for the geodetic MDT models (e.g., Sánchez 2012; Sánchez et al. 2016), therefore, the oceanographic MDT models are constrained to the geodetic MDT models.

In this study, we use the most recently released oceanographic MDT model $\mathrm{ECCO}^{4}-\mathrm{v} 4 \mathrm{r} 3$, which covers the period from 1992 to 2015 (Forget et al. 2015; Fukumori et al. 2017). Among its characteristics, the ECCO-v4 MDT model is the first multidecadal ECCO estimate that is truly global, including the Arctic Ocean. Using a nonlinear free surface formulation and real freshwater flux boundary condition, this model enjoys a more accurate simulation of sea level change. Table 2 summarizes the observations employed in Release 3 of this MDT model.

In order to quantify the effect of the selected MDT model on the estimation of $W_{0}$, we also used the former version of ECCO products called ECCO-2 (Menemenlis et al. 2008) that provides the static MDT over the period 1992 to present.

\section{Numerical result and discussion}

All the results are produced based on the solution of Eq. (20) by iteration as explained in "Appendix 2". Besides, as the harmonic series for the geoid height in Eq. (9) needs a correction for the topographic bias of $T^{\mathrm{GGM}}$ at the geoid (e.g., Sjöberg 1977, 2007), in this study, we use the Earth2014, models of Earth's topography, bedrock and ice sheets of $1^{\prime}$ resolution (Hirt and Rexer 2015), to compute the topographic bias correction. According to the input data for the empirical estimation of $W_{0}$, various aspects of those input data are considered to assess the sensitivity of the estimation of $W_{0}$ to the employed data.

\footnotetext{
${ }^{4}$ Estimating the Circulation and Climate of the Ocean.
} 
Table 2 Observations utilized underpinning the ECCO-v4r3 (cf. Fukumori et al. 2017)

\begin{tabular}{lc}
\hline Variable & Observations/models \\
\hline Sea level & T/P over 1993-2005, J1 over \\
& 2002-2008, J2 over 2008-2015, \\
& Geosat Follow-On over 2001-2007, \\
& CryoSat-2 over 2011-2015, ERS1/2 \\
over 1992-2001, ENVISAT over & 2002-2012, SARAL/AltiKa over \\
& 2013-2015 \\
& Argo floats over 1995-2015, XBTs \\
& over 1992-2008, CTDs over \\
Temperature profiles & ITP2-2011, SEaOS over 2004-2010, 2004-2011 \\
& Argo floats over 1997-2015, CTDs \\
& over 1992-2011, SEaOS over \\
Salinity profiles & 2004-2010 \\
& AVHRR over 1992-2013, AMSR-E \\
Sea surface temperature & over 2002-2010 \\
Aquarius over 2011-2013 & SSM/I DMSP-F11 over 1992-2000, \\
Sea surface salinity & SSM/I DMSP-F13 over 1995-2009, \\
Sea-ice concentration & SSMIS DMSP-F17 over 2006-2015 \\
GRACE over 2002-2014 & World Ocean Atlas 2009 \\
Ocean bottom pressure & DTU13MDT \\
Mean dynamic & \\
topography & \\
\hline
\end{tabular}

\subsection{Effect of the Earth's gravity field model on the estimation of $W_{0}$}

Considering the role of model of the Earth's gravity field in the estimation of $W_{0}$, three different aspects of the gravity field are considered: (1) contribution of the omission error of the GGM, (2) influence of the selected GGM and (3) dependence of $W_{0}$ to the time-dependent Earth's gravity field changes. To be consistent with the resolutions of the International Association of Geodesy, IAG (Tscherning 1984), all the estimations in this study are based on the zero-tide system for the GGMs. Therefore, all free-tide GGMs are converted to the zero-tide GGMs (the XGM2016 and GOCO05c models are provided in zero-tide system). Since sun and moon are moving relatively close to the Earth's equatorial plane, therefore, there is a latitude-dependent relation between permanent tides and the SHCs of the Earth's gravity field (Ekman 1989). This implies that only zonal coefficients of the Earth's gravity field are affected by the permanent tides. As explained by Gruber et al. (2014), only the second-degree zonal coefficient, $\mathrm{C}_{20}$, is taken into account for the conversion between the zero-tide and tide-free systems:

$\bar{C}_{20}^{\mathrm{ZT}}-\bar{C}_{20}^{\mathrm{TF}}=k_{20}\left\langle\Delta \bar{C}_{20}\right\rangle$, where $\left\langle\Delta \bar{C}_{20}\right\rangle=-1.391412 \times 10^{-8}$ is the average value of the second-degree zonal tidal correction for sun and moon and $k_{20}=0.30190$ is the loading Love number for seconddegree zonal coefficient.

\subsubsection{Influence of the omission error of the GGM in the estimation of $W_{0}$}

To quantify the influence of omission error of the GGMs in $W_{0}$, EIGEN-6C4 GGM that provides SHCs of the Earth's gravity field to degree/order 2190/2190 has been examined. To do so, $W_{0}$ is estimated firstly using the maximum possible spectral resolution of the Earth's gravity field $(n=2190)$. In the next step, $W_{0}$ is computed based on the maximum degree of the SHCs altering between 10 and 2190. Figure 1 shows how $\delta W_{0}=W_{0}^{\{n=2190\}}-W_{0}^{\left\{n=n_{\max }\right\}}$ changes while the maximum degree of the spherical harmonics expansion varies between 10 and 730 in computing $N^{\mathrm{GGM}}$, Eq. (18). The computations are carried out based on ECCO2 and DTU18MSS as MDT and MSS models, respectively. Assuming that the errors in the input data act in the same way in the estimation of $W_{0}$ while changing the maximum degree $n_{\max }$, one can attribute the differences in the estimated $W_{0}$ s only to the omission error (Fig. 1).

A closer look at the estimated $\delta W_{0}$ s reveals that unlike the previous studies that examined other approaches to estimate $W_{0}$ (Sánchez 2007; Burša et al. 2007a; Dayoub et al. 2012; Sánchez et al. 2014, 2016), only satellite-based coefficients of the GGM do not suffice to estimate $W_{0}$. It is mainly due to taking into account land areas in our computations based on our approach. For $n_{\max }=200$, which roughly corresponds to the satellite-only components of GGM, the omission error is $0.062 \mathrm{~m}^{2} \mathrm{~s}^{-2}$ that accords with an inwards shift of about $-6 \mathrm{~mm}$ in the corresponding equipotential surface. The omission error decreases from $0.028 \mathrm{~m}^{2} \mathrm{~s}^{-2}$ at $n_{\max }=360$ to $0.01 \mathrm{~m}^{2} \mathrm{~s}^{-2}$ at $n_{\max }=720$, corresponding to a difference in displacement of about $-1.9 \mathrm{~mm}$. Considering $n_{\max } \geq 720$ shows that truncating the GGM series expansion at $n_{\max }=1780$ results in an omission error of about $0.001 \mathrm{~m}^{2} \mathrm{~s}^{-2}(-0.1 \mathrm{~mm}$ displacement of the equipotential surface).

\subsubsection{Sensitivity of the $W_{0}$ estimation to the selected GGM}

In order to quantify the effect of the selected GGM on the estimated $W_{0}$, the EGM2008, SGG-UGM-1, EIGEN6C4, EIGEN-6C3stat, GOCO05c and XGM2016 GGMs, all providing the maximum possible spectral resolution of the Earth's gravity field, have been used. Since the omission error declines significantly from $n_{\max }=720$ (Fig. 1), we truncate the spherical harmonics expansion at $n_{\max }=720$ to estimate $W_{0}$ based on the aforementioned GGMs, except for 


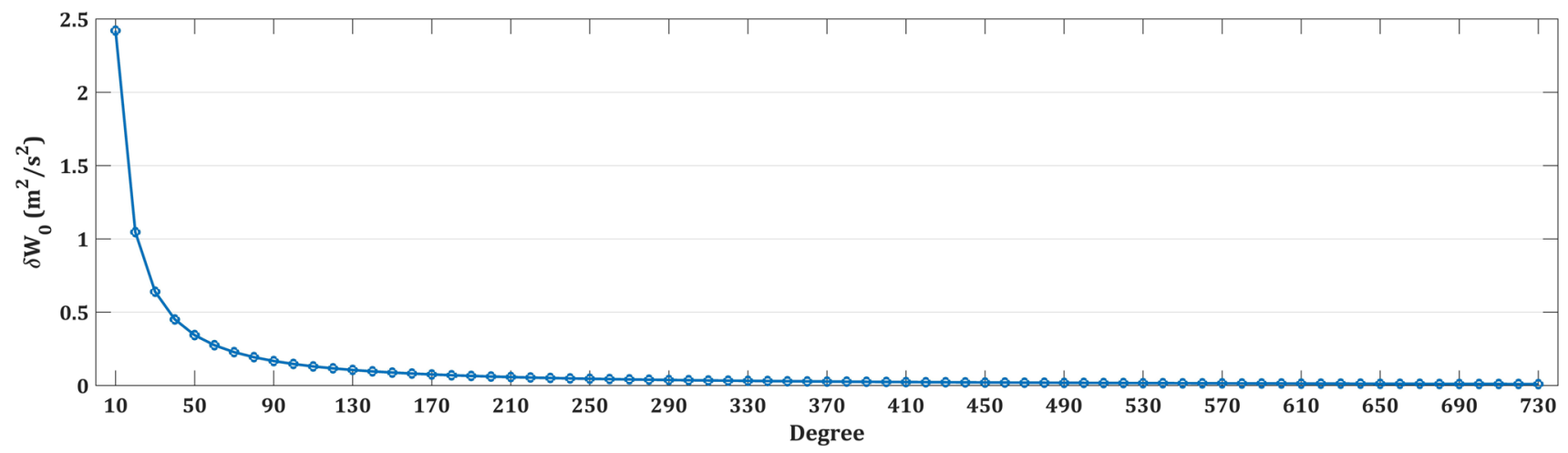

Fig. 1 Influence of the omission error of EIGEN-6C4 GGM in the estimated $W_{0}\left(\delta W_{0}=W_{0}^{\{n=2190\}}-W_{0}^{\left\{n=n_{\max }\right\}}\right)$. The computations are carried out based on ECCO2 and DTU18MSS as MDT and MSS models, respectively

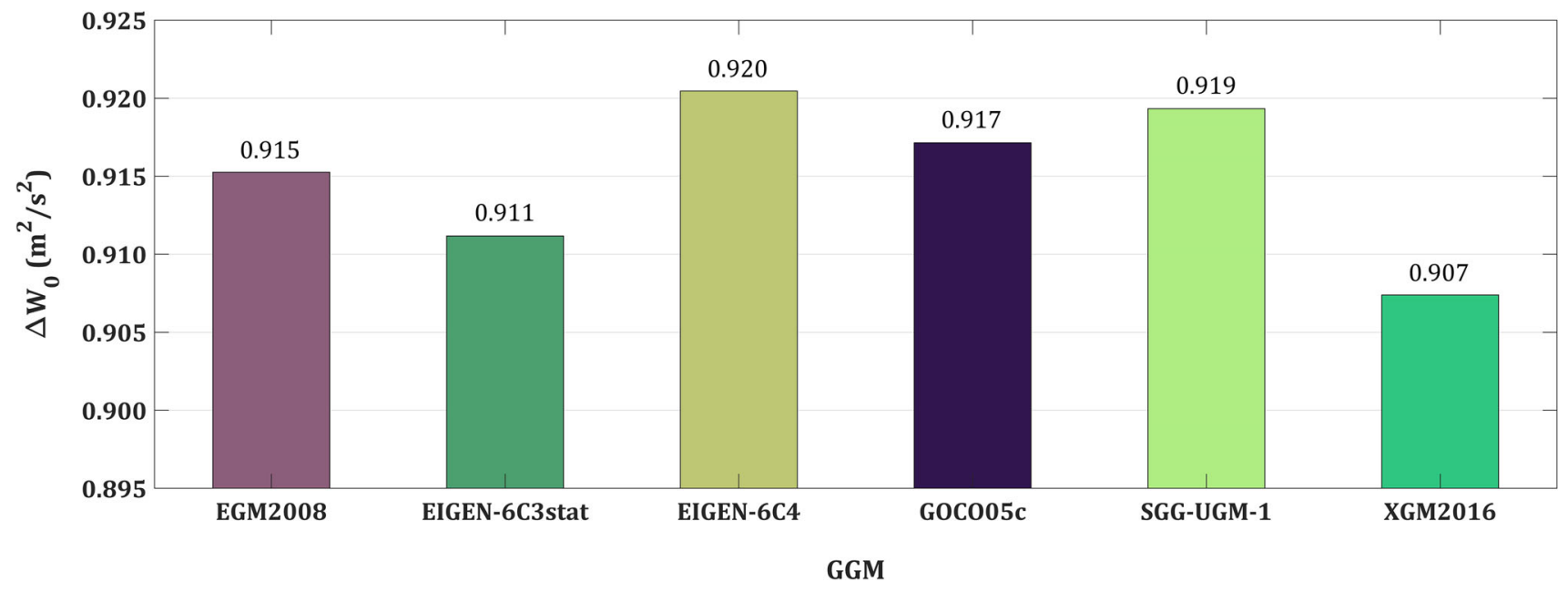

Fig. $2 \mathrm{~W}_{0}$ values estimated based on different global gravity models $\left(\delta W_{0}=W_{0}-62636846\right)$. The computations are conducted based on ECCO2 MDT and DTU18MSS mean sea surface models

the XGM2016 in which the maximum degree/order is 719 . Figure 2 depicts the differences in the estimated values of $W_{0}$ based on various GGMs (note that the constant value $62636846 \mathrm{~m}^{2} \mathrm{~s}^{-2}$ has been removed from all the estimations). The maximum difference between the values based on the EIGEN-6C4 and XGM2016 models amounting to $0.013 \mathrm{~m}^{2} \mathrm{~s}^{-2}(1 \mathrm{~mm}$ displacement of the equipotential surface) shows that the choice of GGM does not play practically a considerable role in the estimation of $W_{0}$. Considering the assumption that the input data are free of errors, the differences in the estimations of $W_{0}$ arise from various processing methodologies as well as the data (both the type and the period of data) applied to define various GGMs. As different combinations of satellite gravity data (GOCE, GRACE and CHAMP), information from kinematic orbits of low Earth orbiting satellites (LEOs), SLR data (like LAGEOS), altimetric gravity anomalies, terrestrial gravity anomalies, and shipborne and airborne measurements contribute to different GGMs, it can lead to various estimations of $W_{0}$. For instance, comparing EGM2008 with SGG-UGM-1, one can see that in EGM2008 only GRACE satellite gravity data have been employed, while the latter has been achieved by combining EGM2008 gravity anomaly and GOCE observation data.

\subsubsection{Dependence of the estimation of $W_{0}$ on the time-dependent Earth's gravity field changes}

Because of the dynamic processes and mass redistribution within the Earth and on or above its surface, the Earth's body undergoes changes at different temporal and spatial scales. Therefore, in addition to the static part, the Earth's gravity field comprises also a time variable part that is quite smaller (e.g., Wahr et al. 1998). Since its launch in 2002, GRACE has provided a valuable source of information about the time variable Earth's gravity field, and more specifically water exchange as the main contributor to the Earth's gravity field changes within decadal scales. As Wahr et al. (1998) described in detail, for periods less than several hundred years, temporal changes in the Earth's gravity field are mainly attributed to the movement of water mass within the Earth's 
relatively thin fluid envelope. Measuring changes in range between two satellites, GRACE mission provides the Earth's gravity field in terms of monthly normalized SHCs (e.g., Tapley et al. 2004).

In order to quantify influence of the time-dependent Earth's gravity field changes in $W_{0}$, we employed GRACEbased monthly solutions over the period January 2003 to December 2016. The computations for assessing this influence are initially carried out using only one MDT model and one MSS model (ECCO2 and DTU18MSS, respectively). The time series of the estimated $W_{0}$ values, shown in Fig. 3, based on the monthly GRACE models show a linear trend of $-9.3 \times 10^{-4} \mathrm{~m}^{2} \mathrm{~s}^{-2}$ year ${ }^{-1}$, corresponding to the rate of displacement of the equipotential surface amounting to $0.095 \mathrm{~mm}$ year $^{-1}$ (1.34 mm displacement of the equipotential surface over the period January 2003 to December 2016).

The influence of secular and seasonal variations of the Earth's gravity field in the estimation of ellipsoidal parameters $a$ and $b$ of the MEE is shown in Fig. 4. Mainly, the redistribution of water masses, in particular from high latitudes to equatorial areas, causes an upward trend of about $0.035 \mathrm{~mm}_{\text {year }}{ }^{-1}$ in the semi-major axis of the MEE and a downward trend of about $0.136 \mathrm{~mm}_{\text {year }}{ }^{-1}$ in the semi-minor axis $\left(2.61 \times 10^{-11}\right.$ year $^{-1}$ the rate of flattening), confirming an increase in the Earth's dynamic oblateness (e.g., Cheng et al. 2011, 2013; Cheng and Ries 2018).

\subsection{Effect of the mean sea surface on the estimation of $W_{0}$}

\subsubsection{Dependence of the estimation of $W_{0}$ on the time-dependent sea surface changes}

Sea level changes over time because of water mass exchange among the oceans and continents, ice sheets and atmosphere. As mentioned earlier, water exchange is known as the main contributor to the Earth's gravity field changes within decadal scales. Therefore, the signature of this contributor can also be seen in the monthly sea level anomalies. Moreover, in order to meet the assumption that the model-derived sea surface heights are static over the averaging period, time-dependent factors that affect the sea surface heights underpinning the models are removed (MSS models are computed based on sea surface heights averaged over certain time epochs). This implies that the MSS modeling depends on the period considered for the averaging. Accordingly, we also aimed at evaluating the influence of time-dependent sea surface changes in $W_{0}$. To do so, we examined the monthly sea level anomalies over the period January 1993 to December 2017 provided by AVISO along with MSS_CNES_CLS2015 as the reference model that must be restored to the monthly anomalies. According to the estimated time series of $W_{0}$ (Fig. 5) achieved after applying monthly sea level anomalies, the rate of $W_{0}$ change is $-0.027 \mathrm{~m}^{2} \mathrm{~s}^{-2}$ year $^{-1}$. Considering the assumption that all the input data are free of errors, this downward rate reflects the rate of global mean sea level rise amounting to $+3.1 \mathrm{~mm} \mathrm{year}^{-1}$ (WCRP Group 2018). As the sea surface is roughly an equipotential, coinciding on average to the geoid (whose shape is ruled by the gravity field), we can compare the geopotential change with the sea level change over a specific period. The geopotential values of the equipotential surfaces fitting to the mean sea levels in January 1993 and December 2017 are 62636847.077 and $62636846.316 \mathrm{~m}^{2} \mathrm{~s}^{-2}$, respectively, with a difference of $0.761 \mathrm{~m}^{2} \mathrm{~s}^{-2}$ that corresponds to an outwards displacement of the corresponding equipotential surface of approximately $78 \mathrm{~mm}$. These results are in agreement with the global mean sea level rise of about $77.5 \mathrm{~mm}$ in 25 years over the same period.

Applying the yearly MSS models over the same period results also in a downward rate of $-0.027 \mathrm{~m}^{2} \mathrm{~s}^{-2}$ year $^{-1}$. In spite of using different methodology in the estimation of $W_{0}$, this rate of changes is in agreement with those reported by Sánchez et al. (2016) over the period 1993-2013, Dayoub et al. (2012) for period 1992.9-2009 and Sánchez (2007) over the period 1993-2001. Considering the effect of sea level rise, Sánchez et al. (2016) reported a difference of $-0.4117 \mathrm{~m}^{2}$ $\mathrm{s}^{-2}$ between the geopotential values corresponding to the equipotential surfaces coinciding with the mean sea surfaces in 1993 and 2010. By applying yearly MSS models, mirroring the global mean sea level rise, our results show a difference of $-0.3858 \mathrm{~m}^{2} \mathrm{~s}^{-2}$ for the same period. The discrepancy of $0.0259 \mathrm{~m}^{2} \mathrm{~s}^{-2}$ between the results of studies is due to applying different methods as well as utilizing different input data.

\subsubsection{Sensitivity of the $W_{0}$ estimation to the selected mean sea surface model}

In order to evaluate the effect of selected MSS model on the estimation of $W_{0}$, two different MSS models have been examined, MSS_CNES_CLS2015 and DTU18MSS. Focusing on the use of geodetic missions of ERS-1, CryoSat-2 and Jason-1 in CNES_CLS2015 MSS, in comparison with the previous model CNES_CLS 2011, a significant improvement has been achieved in terms of the model coverage over the Arctic zone. DTU18MSS mean sea surface is the latest release of the global high-resolution mean sea surface from DTU Space. The major improvement of the DTU18MSS is the use of 3 years of Sentinel-3A and an improved 7-year CryoSat-2 LRM record.

Since the MSS_CNES_CLS2015 model provides data over $80^{\circ} \mathrm{S}-84^{\circ} \mathrm{N}$ latitudinal coverage, to be able to compare the $W_{0}$ values, computations based on the DTU18MSS model have also been performed over the same latitudinal coverage of MSS_CNES_CLS2015 model. The model 


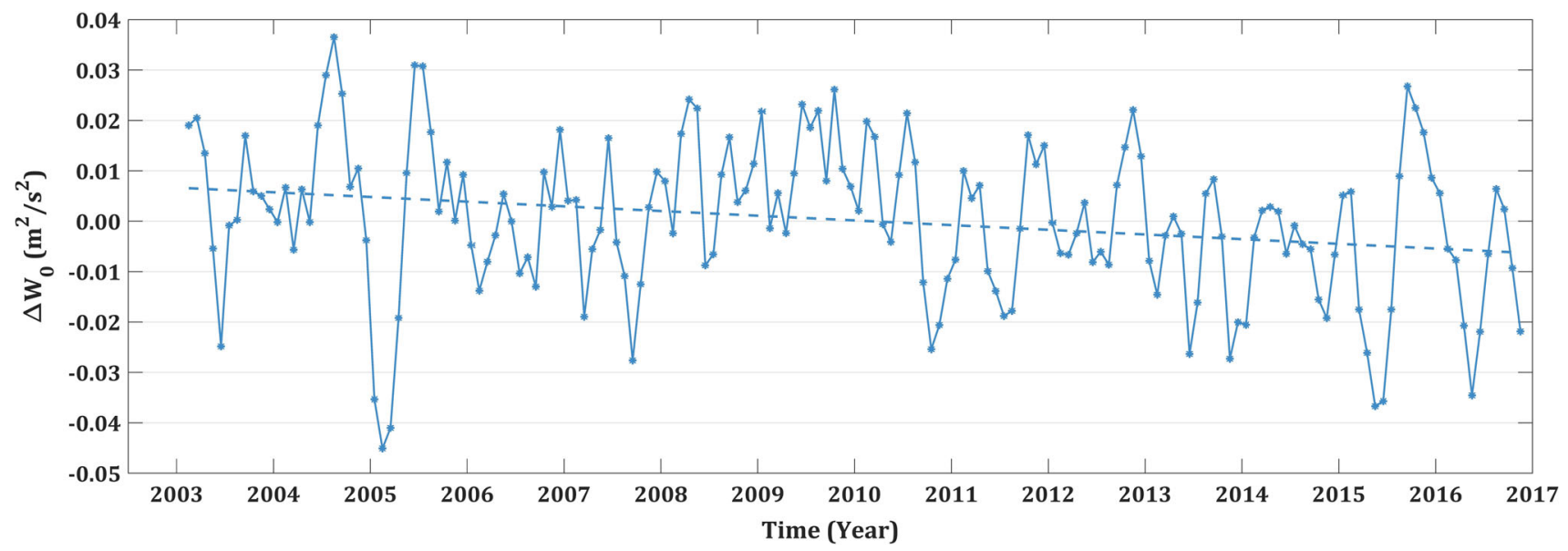

Fig. 3 Time series of the estimated $W_{0}$ values after applying monthly GRACE models based on GFZ R05 solutions. The computations are performed based on ECCO2 MDT and DTU18MSS mean sea surface models. The linear trend of $W_{0}$ is $-9.3 \times 10^{-4} \mathrm{~m}^{2} \mathrm{~s}^{-2}$ year -1 (dashed line)
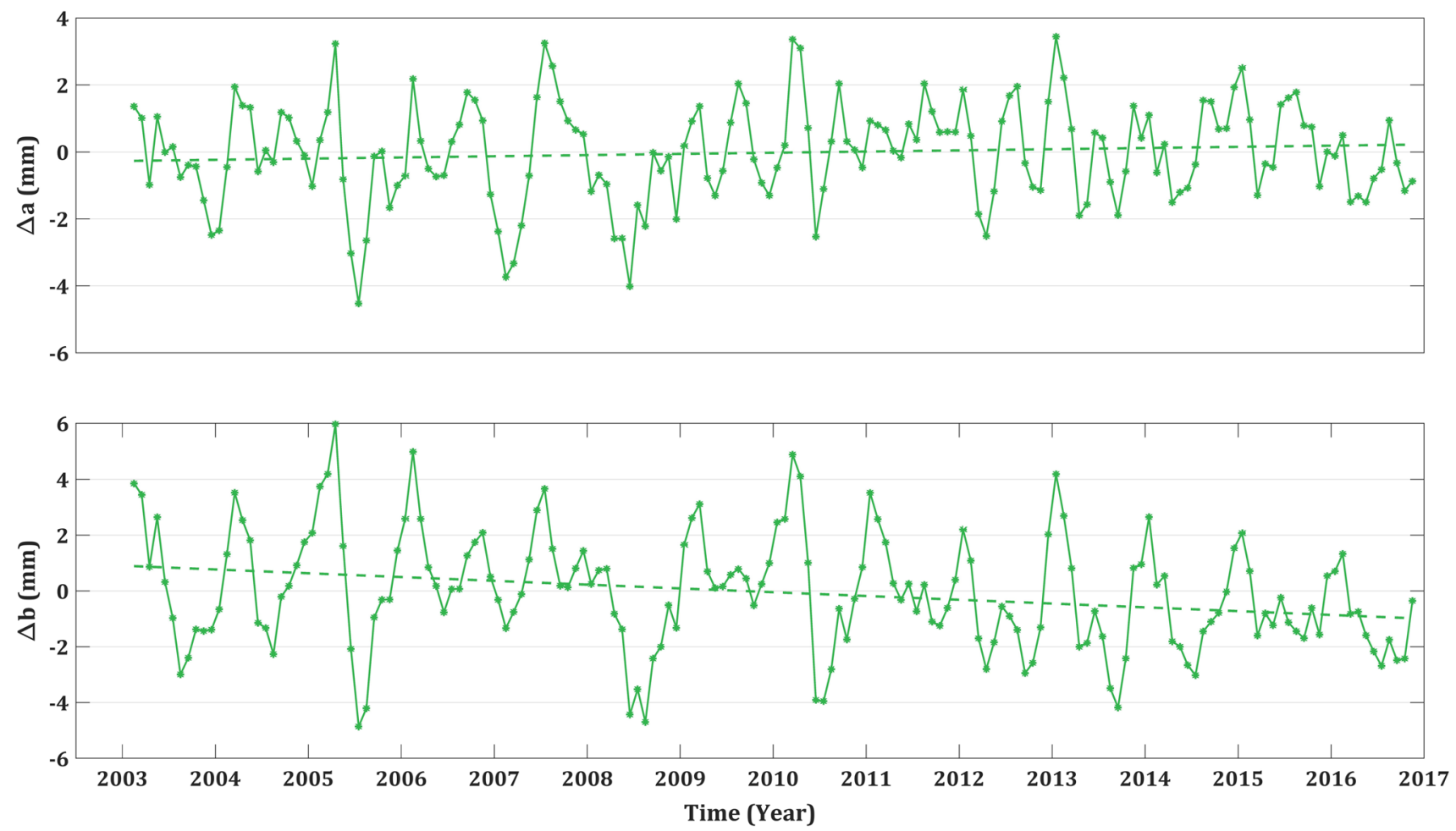

Fig. 4 Time series of the estimated ellipsoidal parameters $a$ and $b$ of the MEE after applying monthly GRACE models based on GFZ R05 solutions. The computations are performed based on ECCO2 MDT and
DTU18MSS mean sea surface models. The linear trends of semi-major and semi-minor axes are $+0.035 \mathrm{~mm}$ year $^{-1}$ and $-0.136 \mathrm{~mm}$ year $^{-1}$, respectively (dashed lines)
MSS_CNES_CLS2015 resulted in $62636846.926 \mathrm{~m}^{2} \mathrm{~s}^{-2}$, while the estimated value of $W_{0}$ based on the model DTU18MSS, amounting to $62636846.628 \mathrm{~m}^{2} \mathrm{~s}^{-2}$, is $0.297 \mathrm{~m}^{2} \mathrm{~s}^{-2}$ smaller, corresponding to a level difference of approximately $30.5 \mathrm{~mm}$ that reflects the mean difference between the MSS models (note that the computations are performed based on ECCO2 MDT and EIGEN-6C4 GGM). Sánchez et al. (2016) considered the former versions of the aforementioned models (called MSS_CNES_CLS11 and DTU10MSS) and by truncating the latitudinal coverage of the models at various latitudes concluded that the total area covered by the MSS model should be employed to estimate 


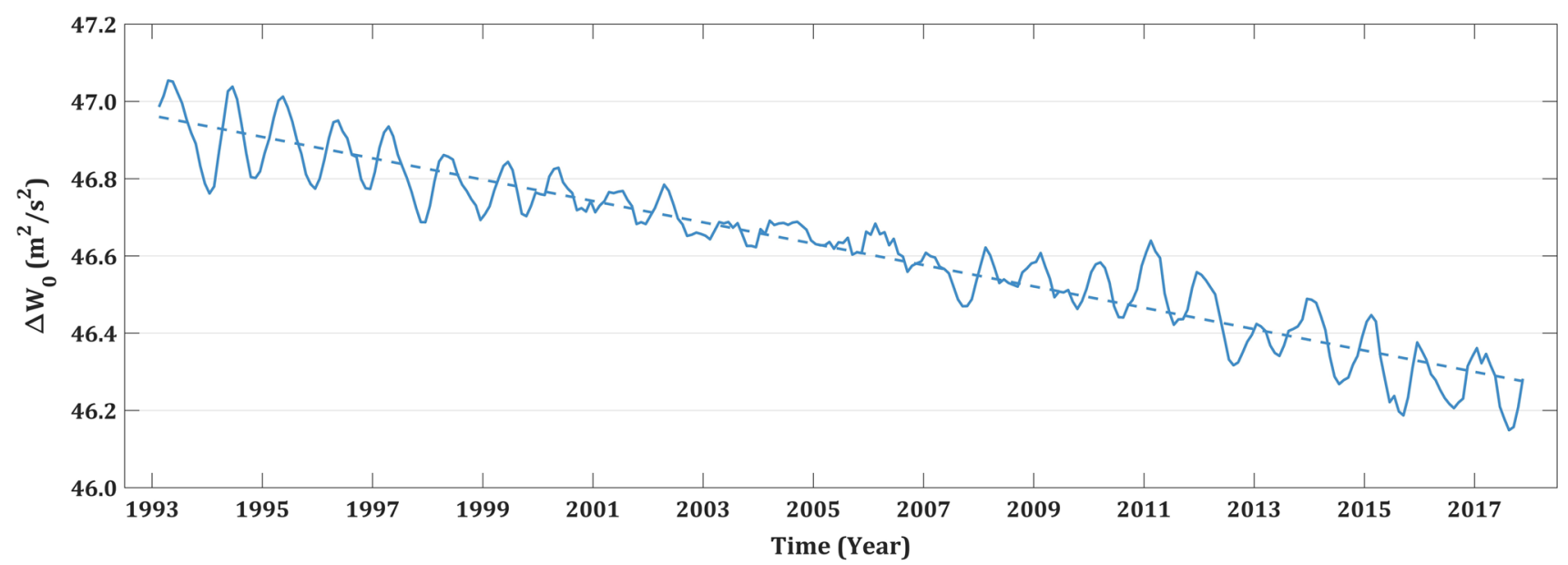

Fig. 5 Time series of the estimated $W_{0}$ values after applying monthly sea level anomalies over the period January 2003 to December 2017. The computations are performed based on ECCO2 MDT and EGM2008

$W_{0}$. Moreover, in this study our target function $I$ (Eq. 17) has to be a minimum when integrating all over the unit sphere. Therefore, our final results are presented based on the DTU18MSS model that provides a global coverage of the mean sea level values.

\subsection{Sensitivity of the $W_{0}$ estimation to the mean dynamic topography model}

All the computations carried out so far were based on the ECCO2 MDT model. In order to evaluate the influence of the selected MDT model in estimation of $W_{0}$, the newest version of the ECCO products has been examined as well. Figure 6 depicts the regional distribution of the discrepancies between mean dynamic topography values based on the models.

Computations implemented based on the EIGEN-6C4 GGM, DTU18MSS MSS and ECCO-v4 MDT resulted in $W_{0}=62636848.102 \mathrm{~m}^{2} \mathrm{~s}^{-2}$ that is $1.182 \mathrm{~m}^{2} \mathrm{~s}^{-2}$ larger than that estimated based on ECCO2 MDT. Unlike the direct approach, in which Sánchez et al. (2016) and Dayoub et al. (2012) concluded that a MDT model is not essential to estimate $W_{0}$, our approach shows a high sensitivity to the choice of MDT model when all the ocean areas are taken into account in the estimation of $W_{0}$. This level of discrepancy in the estimation of $W_{0}$ based on different MDT models mirrors different types of observations, different models that have
GGM. Note that a constant value $62636800 \mathrm{~m}^{2} \mathrm{~s}^{-2}$ must be added to the estimated $\Delta W_{0}$. The rate of $W_{0}$ change is $-0.027 \mathrm{~m}^{2} \mathrm{~s}^{-2}$ year ${ }^{-1}$ (dashed line)

been employed underpinning the MDT models and different approaches for the data processing. Since ECCO-v4 provides a more accurate simulation of sea level change (Fukumori et al. 2017), it is chosen in our approach in estimating $W_{0}$ and the ellipsoidal parameters of the MEE.

\subsection{Sensitivity of the $W_{0}$ and MEE geometrical parameters estimation to the input data accuracy}

According to the error propagation law, in this study, we evaluated the effect of input data accuracy on the estimation of $W_{0}$ and the MEE geometrical parameters. Based on the different variables contributing to the computations, the influence of formal errors of the DTU18MSS MSS, ECCOv4 MDT, EIGEN-6C4 GGM and the uncertainty of the geocentric gravitational constant have been considered. The uncertainty of GGM-based geoid height is a result of omission and commission errors and also the uncertainty of GM. It should be noted that we ignored the covariance between spherical harmonic coefficients of various degree and order and only the variances of SHCs have been taken into account. Over oceans, the standard uncertainty of altimetry-based geoid heights was simply estimated using the formal errors of MSS and MDT models as follows: 


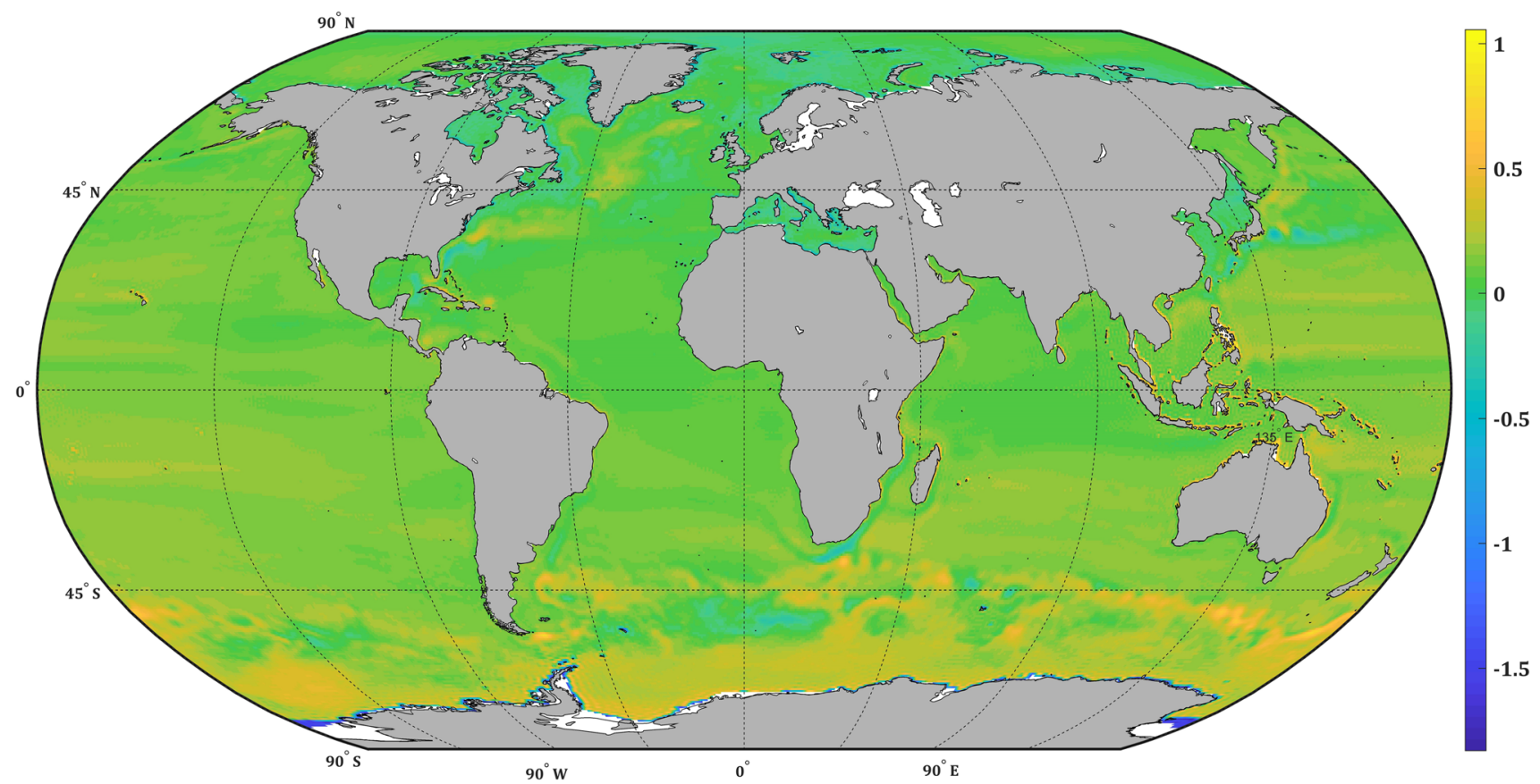

Fig. 6 Regional distribution of the differences between mean dynamic topography values based on the ECCO-v4r03 and ECCO2 MDT models (unit: meter)

$\sigma_{N \text { alt }}^{2}=\sigma_{\mathrm{MSS}}^{2}+\sigma_{\mathrm{MDT}}^{2}$,

where $\sigma_{\text {MSS }}$ represents the formal error of mean sea surface values and $\sigma_{\mathrm{MDT}}$ is the formal error of the used MDT model. It is worth mentioning that in spite of the fact that satellite altimetry observations have been used underpinning the ECCO-v4 MDT (Table 2), correlations between MDT values and MSS values have been neglected. Consequently, based on Eqs. (35) and (36) presented in "Appendix 2", the variancecovariance matrix of unknowns is computed. One should note that the computed formal standard deviations do not include systematic errors from the data (e.g., a possible systematic altimeter calibration error). Burša et al. (2007a) proposed an uncertainty of $\pm 0.5 \mathrm{~m}^{2} \mathrm{~s}^{-2}$ for the estimated $W_{0}$ corresponding to the impact of the systematic altimeter calibration error of 20-30 mm. Considering the TOPEX/POSEIDON absolute bias of $\pm 15 \mathrm{~mm}$, Dayoub et al. (2012) suggested a standard deviation of $\pm 0.2 \mathrm{~m}^{2} \mathrm{~s}^{-2}$ as an appropriate value for the estimated $W_{0}$.

The results are as follows (Table 3):
Here, the estimated semi-major and semi-minor parameters of the MEE are 0.678 and $0.650 \mathrm{~m}$ larger than those of GRS80 reference ellipsoid, respectively. It should also be noted that the unknowns have been estimated after three iterations based on the solution provided in "Appendix 2". Moreover, inserting the estimated values into Eq. (22), a new estimate for $G M$ was obtained as:

$\widehat{\mathrm{GM}}=(398600460.55 \pm 0.03) \times 10^{6} \mathrm{~m}^{3} \mathrm{~s}^{-2}$.

The formal standard error of $\widehat{\mathrm{GM}}$ has been estimated using the computed variance-covariance matrix of unknowns.

Table 4 summarizes the findings of some studies that aimed to estimate $W_{0}$ and compares the estimated values in terms of the differences in the equipotential surfaces.

As can be seen, while using the same input data as in Sánchez et al. (2016), our estimated $W_{0}$ value is $6.7 \mathrm{~m}^{2}$ $\mathrm{s}^{-2}$ smaller, and this discrepancy can most likely be referred to the use of different methods. However, considering our approach along with employing the most recently

Table 3 The geoid potential and MEE geometrical parameters achieved based on our approach

The results are based on the EIGEN-6C4 GGM, DTU18MSS MSS, and ECCO-v4 MDT

$W_{0}=62636848.102 \pm 0.004 \mathrm{~m}^{2} \mathrm{~s}^{-2}$

$a=6378137.678 \pm 0.0003 \mathrm{~m}$

$b=6356752.966 \pm 0.0005 \mathrm{~m}$ 
Table 4 The estimated $W_{0}$ s from various studies and the differences in the equipotential surfaces based on the computed $W_{0}$ values

\begin{tabular}{|c|c|c|c|c|c|}
\hline & $W_{0}\left(m^{2} s^{-2}\right)$ & $\begin{array}{l}\text { Level } \\
\text { difference }\end{array}$ & MSS model & MDT model & EGM model \\
\hline & 62636846.7 & & DTU10MSS & $\mathrm{ECCO} 2$ & EGM2008 \\
\hline $\begin{array}{l}\text { This study } \\
\text { (Our Approach) }\end{array}$ & 62636846.9 & & DTU18MSS & $\mathrm{ECCO} 2$ & EIGEN-6C4 \\
\hline & 62636848.1 & & DTU18MSS & ECCOv4 & EIGEN-6C4 \\
\hline Sánchez et al. (2016) & 62636853.4 & $54 \mathrm{~cm}$ & DTU10MSS & $\mathrm{ECCO} 2$ & EGM2008 \\
\hline Dayoub et al. (2012) & 62636854.2 & & DNSC08 & $\mathrm{ECCO} 2$ & EGM2008 \\
\hline $\begin{array}{l}\text { Čunderlík and Mikula } \\
(2009)\end{array}$ & 62636857.95 & $10 \mathrm{~cm}$ & CLS01 & N.A. & $\begin{array}{l}\text { EIGEN- } \\
\text { GC03 }\end{array}$ \\
\hline Sánchez (2007) & 62636854.4 & $2 \mathrm{cr}$ & KMS04 & N.A. & EGM96 \\
\hline Bursa et al. (2007b) & 62636854.6 & $10 \mathrm{~cm}$ & $\mathrm{~T} / \mathrm{P}(2003-2003)$ & Not significant & EGM96 \\
\hline Bursa et al. (1998b) & 62636855.61 & & T/P (1993-1996) & Not significant & EGM96 \\
\hline Rapp (1995) & 62636856.88 & $13 \mathrm{~cm}$ & $\begin{array}{l}\text { Best fitting for } \\
T / P \text { sea surface }\end{array}$ & N.A. & N.A. \\
\hline $\begin{array}{l}\text { IERS Convention } \\
1996 \text { (McCarthy 1996) }\end{array}$ & 62636856.85 & & N.A. & N.A. & N.A. \\
\hline $\begin{array}{l}\text { IERS Standards } 1992 \\
\text { (McCarthy 1992) }\end{array}$ & 62636860.0 & & N.A. & N.A. & N.A. \\
\hline Moritz (2000): GRS80 & 62636860.85 & & N.A. & N.A. & N.A. \\
\hline
\end{tabular}

released versions of MSS and MDT models resulted in a + $1.4 \mathrm{~m}^{2} \mathrm{~s}^{-2}$ difference comparing with utilizing ECCO2 and DTU10MSS models, which reveals the influence of input data in the estimation of $W_{0}$.

\section{Conclusions}

The determination of $W_{0}$ should be in concordance with the determination of the mean Earth ellipsoidal parameters. In this study, we employed a new strategy to estimate the geopotential value of the equipotential surface fitting to the mean sea level, as well as the geometrical parameters of the reference mean Earth ellipsoid. Based on the various types of input data into the computations, different GGMs, different MSS models and different MDT models have been examined to quantify the dependency of estimations on the differences in the treatment of the input data. Moreover, since $W_{0}$ should be considered as a time-independent reference parameter, the influences of the time-dependent gravity field and sea surface changes have been considered in the estimates. According to the achieved results, our approach is highly sensitive to the MDT and MSS models, and consequently to the satellite altimetry-derived geoid height. On the contrary, the selection of the global gravity field model does not play a significant role in the estimation of $W_{0}$.

Sánchez et al. (2016) investigated the use of the newest gravity field and MSS models and used standardized data and procedures to provide a new estimate of the potential, $W_{0}=62636853.4 \pm 0.02 \mathrm{~m}^{2} \mathrm{~s}^{-2}$, that differs by - $2.6 \mathrm{~m}^{2} \mathrm{~s}^{-2}$ from the most accepted value $62636856.0 \pm 0.5 \mathrm{~m}^{2} \mathrm{~s}^{-2}$, i.e., the $W_{0}$ in the IERS conventions (McCarthy and Petit 2004, Table 1.1). However, our new estimate $W_{0}=62636848.102 \mathrm{~m}^{2} \mathrm{~s}^{-2}$ provides a discrepancy of $5.3 \mathrm{~m}^{2} \mathrm{~s}^{-2}$ with respect to that of Sánchez et al. (2016). In our approach, the mean Earth ellipsoid parameters have jointly been determined with $W_{0}$ using a least squares adjustment scheme. Accordingly, $a=6378137.678 \mathrm{~m}$ 
and $b=6356752.966 \mathrm{~m}$ are 0.678 and $0.652 \mathrm{~m}$ larger than the semi-major and semi-minor axes, respectively, of GRS80 reference ellipsoid. The differences to previous reported values, both in $W_{0}$ and in MEE parameters, are due both to more recent sea level data and to a significant improvement in data, which led to a more precise evaluation. In addition, the new estimated $W_{0}$ value is also due to the changed GM value in which a new estimation for the geocentric gravitational constant was obtained as $\mathrm{GM}=$ $(398600460.55 \pm 0.03) \times 10^{6} \mathrm{~m}^{3} \mathrm{~s}^{-2}$. One can see that the standard error of this new value is less than that mentioned in Sjöberg (2013) included in Groten (2004), which was the best-known GM value at that time. In choosing a geodetic reference system, each parameter should be constant, referring to a specific epoch/datum, attached with a parameter describing its temporal change for possible extrapolation to an arbitrary epoch.

Acknowledgements Open access funding provided by University of Gävle. The support provided by Ole Baltazar Andersen at DTU space in providing us with the DTU18MSS mean sea surface model is highly appreciated. We would also like to thank Ou Wang from NASA Jet Propulsion Laboratory (JPL) for his support and valuable comments during analyzing MDT datasets. Special thanks go to the Editor-in-Chief, associate editor and three anonymous reviewers. Their constructive comments and suggestions for amendment have significantly improved the article.

Author contributions Lars E. Sjöberg designed research; Hadi Amin performed research; Hadi Amin, Mohammad Bagherbandi and Lars E. Sjöberg analyzed data; Hadi Amin wrote the draft paper; Lars E. Sjöberg and Mohammad Bagherbandi commented on the draft; Hadi Amin finalized the paper.

Data availability The datasets analyzed during the current study are available from: All the static Earth's Global Gravity Models through the http://icgem.gfz-potsdam.de/home/. Monthly GFZ Release-05a GRACE Level-2 data products through the ftp://podaac-ftp.jpl.nasa. gov/allData/grace/L2/GFZ/RL05. MSS_CNES_CLS2015 model and monthly sea level anomalies through the https://www.aviso.altimetry.fr/ en/data/products/auxiliary-products/mss.html. DTU18MSS mean sea surface model through ftp://ftp.space.dtu.dk/pub/DTU18. ECCO$\mathrm{v} 4 \mathrm{r} 3$ mean dynamic topography model through ftp://ecco.jpl.nasa. gov/Version4/Release3/. ECCO_2 mean dynamic topography model through ftp://ecco.jpl.nasa.gov/ECCO2/. Earth2014, models of Earth's topography, bedrock and ice sheets through http://ddfe.curtin.edu. au/models/Earth2014/. In addition, the datasets generated during the current study are available from the corresponding author on reasonable request.

Open Access This article is distributed under the terms of the Creative Commons Attribution 4.0 International License (http://creativecomm ons.org/licenses/by/4.0/), which permits unrestricted use, distribution, and reproduction in any medium, provided you give appropriate credit to the original author(s) and the source, provide a link to the Creative Commons license, and indicate if changes were made.

\section{Appendix 1}

As explained in Sect. 2.2.1, target function $J$ (Eq. 15) can be represented as a sum over ocean-covered and land-covered parts of the Earth:

$$
\begin{aligned}
J= & \frac{1}{4 \pi} \iint_{\sigma_{1}}\left[r_{1}(\beta)+N-r_{E}(a, e, \beta)\right]^{2} \mathrm{~d} \sigma \\
& +\frac{1}{4 \pi} \iint_{\sigma_{2}}\left[r_{1}(\beta)+N-r_{E}(a, e, \beta)\right]^{2} \mathrm{~d} \sigma=\min .(a, e),
\end{aligned}
$$

where $\sigma_{1}$ and $\sigma_{2}$ represent ocean-covered and land-covered parts of the unit sphere, respectively. Therefore, as both satellite altimetry and a GGM model can contribute over oceans to estimate the geoid height, using Eqs. (8) and (9) as well as defining weighting coefficient $p$ (see Eq. 19) lead to:

$$
\begin{aligned}
J= & \frac{1}{4 \pi} p \iint_{\sigma_{1}}\left[r_{1}(\beta)+N^{\mathrm{alt}}-r_{E}(a, e, \beta)\right]^{2} \mathrm{~d} \sigma \\
& +\frac{1}{4 \pi}(1-p) \iint_{\sigma_{1}}\left[r_{1}(\beta)+N^{\mathrm{GGM}}+\frac{U_{1}-W_{0}}{\gamma_{1}}-r_{E}(a, e, \beta)\right]^{2} \mathrm{~d} \sigma \\
& +\frac{1}{4 \pi} \iint_{\sigma_{2}}\left[r_{1}(\beta)+N^{\mathrm{GGM}}+\frac{U_{1}-W_{0}}{\gamma_{1}}-r_{E}(a, e, \beta)\right]^{2} \mathrm{~d} \sigma=\min .(a, e) .
\end{aligned}
$$

Consequently, target function $I$ can be achieved by augmenting target function $J$ by the extra unknown $x=$ $-\Delta W_{0}=U_{1}-W_{0}$ :

$$
\begin{aligned}
I= & p \iint_{\sigma_{1}}\left[r_{1}(\beta)+N^{\text {alt }}-r_{E}(a, e, \beta)\right]^{2} \mathrm{~d} \sigma \\
& +(1-p) \iint_{\sigma_{1}}\left[r_{1}(\beta)+N^{\mathrm{GGM}}+\frac{x}{\gamma_{1}}-r_{E}(a, e, \beta)\right]^{2} \mathrm{~d} \sigma \\
& +\iint_{\sigma_{2}}\left[r_{1}(\beta)+N^{\mathrm{GGM}}+\frac{x}{\gamma_{1}}-r_{E}(a, e, \beta)\right]^{2} \mathrm{~d} \sigma=\min .(x, a, e) .
\end{aligned}
$$

Finally, introducing $I_{1}, I_{2}$ and $I_{3}$ as Eq. (18) summarizes $I$ in the form of Eq. (17).

\section{Appendix 2}

In this section, we present a modified explicit solution by iteration according to Sjöberg (2013), including some corrections.

\section{Solution by iteration}

The three conditions formed by Eq. (20) are nonlinear in the unknowns $x, a$ and $e$. Starting from initial values for $a$ and 
$e$, denoted $A$ and $E$, from a geodetic reference system (e.g., GRS80) and setting $x$ initially to zero, one may linearize the equations as follows. The radius vector of MEE can be expanded to the first order as:

$r_{E}=r_{0}+r_{a} d A+r_{e} d E$

where

$$
\begin{aligned}
& r_{0}=A \sqrt{1-E^{2} \sin ^{2} \beta} \\
& r_{a}=\left[\frac{\partial r_{E}}{\partial a}\right]_{e=E}=\sqrt{1-E^{2} \sin ^{2} \beta} \\
& r_{e}=\left[\frac{\partial r_{E}}{\partial e}\right]_{\substack{a=A \\
e=E}}=-\frac{A E \sin ^{2} \beta}{\sqrt{1-E^{2} \sin ^{2} \beta}} .
\end{aligned}
$$

Then, by writing the residual geoid height as:

$$
\begin{aligned}
d R^{\text {alt }} & =r_{1}+N^{\text {alt }}-r_{0} \\
d R^{\mathrm{GGM}} & =r_{1}+N^{\mathrm{GGM}}-r_{0}
\end{aligned}
$$

the target function $I$ of Eq. (17) can be written as:

$$
\begin{aligned}
I= & p I_{1}(d A, d E)+(1-p) I_{2}(x, d A, d E) \\
& +I_{3}(x, d A, d E)=\min (x, d A, d E),
\end{aligned}
$$

where

$$
\begin{aligned}
I_{1} & =\iint_{\sigma_{1}}\left[d R^{\text {alt }}-r_{a} d A-r_{e} d E\right]^{2} \mathrm{~d} \sigma \\
I_{2} & =\iint_{\sigma_{1}}\left[d R^{\mathrm{GGM}}+x / \gamma_{1}-r_{a} d A-r_{e} d E\right]^{2} \mathrm{~d} \sigma \\
I_{3} & =\iint_{\sigma_{2}}\left[d R^{\mathrm{GGM}}+x / \gamma_{1}-r_{a} d A-r_{e} d E\right]^{2} \mathrm{~d} \sigma .
\end{aligned}
$$

The least squares solution for $I$ is obtained by equating its derivatives with respect to $x, d A$ and $d E$ to zero, leading to the following matrix system of equations:

$$
\left(\begin{array}{ccc}
F_{x x} & F_{x a} & F_{x e} \\
F_{x a} & F_{a a} & F_{a e} \\
F_{x e} & F_{a e} & F_{e e}
\end{array}\right)\left(\begin{array}{c}
x \\
d A \\
d E
\end{array}\right)=\left(\begin{array}{c}
f_{x} \\
f_{a} \\
f_{e}
\end{array}\right),
$$

where

$$
\begin{aligned}
& F_{x x}=(1-p) \iint_{\sigma_{1}} \frac{\mathrm{d} \sigma}{\gamma_{1}^{2}}+\iint_{\sigma_{2}} \frac{\mathrm{d} \sigma}{\gamma_{1}^{2}} \\
& F_{x a}=-(1-p) \iint_{\sigma_{1}} \frac{r_{a} \mathrm{~d} \sigma}{\gamma_{1}}-\iint_{\sigma_{2}} \frac{r_{a} \mathrm{~d} \sigma}{\gamma_{1}}
\end{aligned}
$$

$$
\begin{aligned}
F_{x e} & =-(1-p) \iint_{\sigma_{1}} \frac{r_{e} \mathrm{~d} \sigma}{\gamma_{1}}-\iint_{\sigma_{2}} \frac{r_{e} \mathrm{~d} \sigma}{\gamma_{1}} \\
F_{a a} & =\iint_{\sigma} r_{a}^{2} \mathrm{~d} \sigma \\
F_{e e} & =\iint_{\sigma} r_{e}^{2} \mathrm{~d} \sigma \\
F_{a e} & =\iint_{\sigma} r_{a} r_{e} \mathrm{~d} \sigma
\end{aligned}
$$

and

$$
\begin{aligned}
& f_{x}=-(1-p) \iint_{\sigma_{1}} \frac{d R^{G G M} \mathrm{~d} \sigma}{\gamma}-\iint_{\sigma_{2}} \frac{\mathrm{d} R^{G G M} \mathrm{~d} \sigma}{\gamma} \\
& f_{a}=\iint_{\sigma_{1}} r_{a}\left[p d R^{a l t}+(1-p) d R^{G G M}\right] \mathrm{d} \sigma+\iint_{\sigma_{2}} r_{a} d R^{G G M} \mathrm{~d} \sigma \\
& f_{e}=\iint_{\sigma_{1}} r_{e}\left[p d R^{a l t}+(1-p) d R^{G G M}\right] \mathrm{d} \sigma+\iint_{\sigma_{2}} r_{e} d R^{G G M} \mathrm{~d} \sigma .
\end{aligned}
$$

After solving for $d A$ and $d E, A$ and $E$ are updated to new values after each iteration:

$A=A+d A$ and $E=E+d E$

and, finally, after the iteration has stopped, $W_{0}$ is estimated as $\hat{W}_{0}=U_{1}-\hat{x}$.

\section{References}

Ågren J (2004) The analytical continuation bias in geoid determination using potential coefficients and terrestrial gravity data. J Geod $78: 314-332$

Andersen O, Knudsen P, Stenseng L (2018a) A new DTU18 MSS mean sea surface-improvement from SAR altimetry. 172. Abstract from 25 years of progress in radar altimetry symposium, 24-29 September 2018, Ponta Delgada, São Miguel Island Azores Archipelago, Portugal

Andersen O, Rose SK, Knudsen P, Stenseng L (2018b) The DTU18 MSS mean sea surface improvement from SAR altimetry. Presented in: International Symposium of Gravity, Geoid and Height Systems (GGHS) 2, The second joint meeting of the International Gravity Field Service and Commission 2 of the International Association of Geodesy, Copenhagen, Denmark, Sep 17-21, 2018

Ardalan A, Grafarend E, Kakkuri J (2002) National height datum, the Gauss-Listing geoid level value $W_{0}$ and its time variation, Baltic Sea Level project: epochs 1990.8, 1993.8, 1997.4. J Geod 76:1-28

Bruns H (1878) Die Figure der Erde. Publ. Preuss. Geod. Inst, Berlin Burša M, Šíma Z, Kostelecky J (1992) Determination of the geopotential scale factor from satellite altimetry. Stud Geoph Geod 36:101-109

Burša M, Radej K, Šima Z, True SA, Vatrt V (1997) Determination of the geopotential scale factor from TOPEX/POSEIDON satellite altimetry. Stud Geophys Geod 41:203-216

Burša M, Kouba J, Radej K, True S, Vatrt V, Vojtîšková M (1998a) Monitoring geoidal potential on the basis of Topex/Poseidon altimeter 
data and EGM96. In: Forsberg R, Feissel M, Dietrich R (eds) Geodesy on the move - gravity, geoid, geodynamics and Antarctica, vol 119. IAG Symposia. Springer, New York, pp 352-358

Burša M, Kouba J, Radej K, True S, Vatrt V, Vojtíšková M (1998b) Mean Earth's equipotential surface from TOPEX/Poseidon altimetry. Studia geoph et Geod 42:456-466. https://doi.org/10.1023/A: 1023356803773

Burša M, Kenyon S, Kouba J, Müller A, Radej K, Vatrt V, Vojtíšková M, Vítek V (1999) Long-term stability of geoidal geopotential from Topex/Poseidon satellite altimetry 1993-1999. Earth Moon Planets 84:163-176

Burša M, Kenyon S, Kouba J, Radej K, Vatrt V, Vojtíšková M, Šimek J (2001) World height system specified by geopotential at tide gauge stations. In: Drewes H, Dodson AH, Fortes LPS, Sánchez L, Sandoval P (eds) Vertical reference systems. IAG Symposia, vol 124. Springer, Berlin, Heidelberg

Burša M, Groten E, Kenyon S, Kouba J, Radej K, Vatrt V, Vojtí̌̌ková M (2002) Earth's dimension specified by geoidal geopotential. Stud Geophys Geod 46:1-8

Burša M, Kenyon S, Kouba J, Šíma Z, Vatrt V, Vítek V, Vojtíšková M (2007a) The geopotential value $\mathrm{W}_{0}$ for specifying the relativistic atomic time scale and a global vertical reference system. J Geod $81: 103-110$

Burša M, Šíma Z, Kenyon S, Kouba J, Vatrt V, Vojtíšková M (2007b) Twelve years of developments: geoidal geopotential $\mathrm{W}_{0}$ for the establishment of a world height system - present state and future. In: Proceedings of the 1st international symposium of the international gravity field service, Harita Genel Komutanligi, Istanbul, pp 121-123

Chen J, Tapley B, Save H, Tamisiea ME, Bettadpur S, Ries J (2018) Quantification of ocean mass change using gravity recovery and climate experiment, satellite altimeter, and Argo floats observations. J Geophys Res Solid Earth 123:10212-10225. https://doi. org/10.1029/2018JB016095

Cheng M, Ries JC (2018) Decadal variation in Earth's oblateness (J2) from satellite laser ranging data. Geophys J Int 212(2):1218-1224. https://doi.org/10.1093/gji/ggx483

Cheng M, Ries JC, Tapley BD (2011) Variations of the Earth's figure axis from satellite laser ranging and GRACE. J Geophys Res 116:B01409. https://doi.org/10.1029/2010JB000850

Cheng M, Tapley BD, Ries JC (2013) Deceleration in the Earth's oblateness. J Geophys Res Solid Earth 118:740-747. https://doi.org/10. 1002/jgrb.50058

Čunderlík R, Mikula K (2009) Numerical solution of the fixed altimetry-gravimetry BVP using the direct BEM formulation. In: Sideris MG (ed) Observing our changing Earth, vol 133. IAG Symposia. Springer, Berlin

Dahle C (2017) Release notes for GFZ GRACE level-2 products version RL05

Dahle C, Flechtner F, Gruber C, Koenig D, Koenig R, Michalak G, Neumayer KH (2012) GFZ GRACE level-2 processing standards document for level-2 product release 0005. Scientific Technical Report-Data, 12/02. Potsdam. https://doi.org/10.2312/gfz.b1031202-25

Dayoub N, Edwards SJ, Moore P (2012) The Gauss-Listing potential value Wo and its rate from altimetric mean sea level and GRACE. J Geod 86(9):681-694. https://doi.org/10.1007/s00190-012-15476

Ekman M (1989) Impacts of geodynamic phenomena on systems for height and gravity. Bull Geod 63(3):281-296

Fecher T, Pail R, Gruber T (2015) Global gravity field modeling based on GOCE and complementary gravity data. Int J Appl Earth Obs Geoinf 35:120-127. https://doi.org/10.1016/j.jag.2013.10.005

Forget G, Campin JM, Heimbach P, Hill CN, Ponte RM, Wunsch C (2015) ECCO version 4: an integrated framework for non-linear inverse modeling and global ocean state estimation. Geosci Model Dev 8:3071-3104. https://doi.org/10.5194/gmd-8-3071-2015

Förste C, Bruinsma SL, Flechtner F, Marty JC, Lemoine JM, Dahle C, Abrikosov O, Neumayer KH, Biancale R, Barthelmes F, Balmino $\mathrm{G}$ (2012) A preliminary update of the direct approach GOCE processing and a new release of EIGEN-6C. In: Presented at the AGU Fall Meeting 2012, San Francisco, USA, 3-7 Dec, Abstract No. G31B-0923

Förste C, Bruinsma SL, Abrikosov O, Lemoine JM, Marty JC, Flechtner F, Balmino G, Barthelmes F, Biancale R (2014) EIGEN-6C4 The latest combined global gravity field model including GOCE data up to degree and order 2190 of GFZ Potsdam and GRGS Toulouse. GFZ Data Serv. https://doi.org/10.5880/ICGEM.2015. 1

Fukumori I, Wang O, Fenty I, Forget G, Heimbach P, Ponte RM (2017) ECCO Version 4 Release 3, http://hdl.handle.net/1721.1/110380

Gauss FW (1828) Bestimmung des Breitenunterschiedes zwischen den Sternwarten von Göttingen und Altona durch Beobachtungen am Ramsdenschen Zenithsector. Vanderschoeck und Ruprecht, Göttingen, pp 48-50

Groten E (2004) Fundamental parameters and current (2004) best estimates of the parameters of common relevance to astronomy, geodesy and geodynamics. J Geod 77:724-731

Gruber T, Abrikosov O., Hugentobler U (2014) GOCE high level processing facility-GOCE standards. European GOCE Gravity Consortium, 4.0, GO-TN-HPF-GS-0111

Heiskanen WH, Moritz H (1967) Physical geodesy. W H Freeman and Co., San Francisco

Hirt C, Rexer M (2015) Earth 2014: 1 arc-min shape, topography, bedrock and ice-sheet models-available as gridded data and degree- 10,800 spherical harmonics. Int J Appl Earth Obs Geoinf 39:103-112. https://doi.org/10.1016/j.jag.2015.03.001

Liang W, Xu X, Li J, Zhu G (2018) The determination of an ultra high gravity field model SGG-UGM-1 by combining EGM2008 gravity anomaly and GOCE observation data. Acta Geodaeticaet Cartographica Sinica 47(4):425-434. https://doi.org/10.11947/j. agcs.2018.20170269

Listing JB (1873) Über unsere jetzige Kenntnis der Gestalt und Grösse der Erde. Nachr. d Kgl Gesellschaft d Wiss und der Georg-AugustUniv, Göttingen, pp 33-98

Martinec Z (1998) Boundary-value problems for gravimetric determination of a precise geoid, vol 73. Lecture Notes in Earth Sciences. Springer, Berlin

Mather RS (1978) The role of the geoid in four-dimensional geodesy. Mar Geodesy 1:217-252

McCarthy DD (1992) IERS standards (1992). IERS Technical Note 13. Central Bureau of IERS - Observatoire de Paris, $163 \mathrm{p}$

McCarthy DD (1996) IERS conventions (1992). IERS Technical Note 21. Central Bureau of IERS - Observatoire de Paris, $101 \mathrm{p}$

McCarthy DD, Petit G (eds.) (2004) IERS Conventions 2003. IERS Technical Note No. 32. Verlag des Bundesamtes für Kartographie und Geodäsie. Frankfurt am Main

Menemenlis D, Campin J, Heimbach P, Hill C, Lee T, Nguyen A, Schodlock M, Zhang H (2008) ECCO2: high resolution global ocean and sea ice data synthesis. Mercat Ocean Q News1 31:13-21

Moore P, Zhang Q, Alothman A (2006) Recent results on modelling the spatial and temporal structure of the Earth's gravity field. Philos Trans R Soc A Math Phys Eng Sci 364:1009-1026

Moritz H (2000) Geodetic reference system 1980. J Geod 74:128-133

Nesvorný D, Šíma Z (1994) Reönement of the geopotential scale factor Ro on the satellite altimetry basis, vol 65. Kluwer Academic Publishers, Norwell, pp 79-88

Pail R, Fecher T, Barnes D, Factor JF, Holmes SA, Gruber T, Zingerle P (2017) Short note: the experimental geopotential model XGM2016. J Geodesy. https://doi.org/10.1007/s00190017-1070-6 
Pavlis NK, Holmes SA, Kenyon SC, Factor JK (2007) Earth gravitational model to degree 2160: status and progress. Presented at the XXIV General Assembly of the International Union of Geodesy and Geophysics, Perugia, Italy $2-13$

Pavlis NK, Holmes SA, Kenyon SC, Factor JK (2012) The development of the Earth Gravitational Model 2008 (EGM2008). J Geophys Res 117:B04406. https://doi.org/10.1029/2011JB008916

Pavlis NK, Holmes SA, Kenyon SC, Factor JK (2013) Correction to "The development of the Earth Gravitational Model 2008 (EGM2008)". J Geophys Res 118:2633. https://doi.org/10.1002/ jgrb. 50167

Pujol M-I, Schaeffer P, Faugère Y, Raynal M, Dibarboure G, Picot N (2018) Gauging the improvement of recent mean sea surface models: a new approach for identifying and quantifying their errors. J Geophys Res Oceans 123:5889-5911. https://doi.org/10.1029/ 2017JC013503

Rapp RH (1995) Equatorial radius estimates from TOPEX altimeter data. Festschrift Erwin Groten, Inst. of Geodesy and Navigation, University FAF Munich, Neubiberg, P90-97

Rapp RH, Nerem RS, Shum CK, Klosko SM, Williamson RG (1991) Consideration of permanent tidal deformation in the orbit determination and data analysis for the Topex/Poseidon mission. NASA technical memorandum $100775.11 \mathrm{p}$

Sacerdote F, Sansó F (2004) Geodetic boundary value problems and the height datum problem, vol 127. IAG Symposia. Springer, Berlin, pp 174-178

Sánchez L (2007) Definition and realisation of the SIRGAS vertical reference system within a globally unified height system. Dyn Planet Monit Underst Dyn Planet Geod Oceanogr Tools 130:638-645

Sánchez L (2009) Strategy to establish a global vertical reference system. In: Drewes H (ed) Geodetic reference frames, vol 134. IAG symposia. Springer, Berlin

Sánchez L (2012) Towards a vertical datum standardization under the umbrella of global geodetic observing system. J Geod Sci 2(4):325-342

Sánchez L, Dayoub N, Cunderlík R, Minarechová Z, Mikula K, Vatrt V, Vojtíšková M, Šíma Z (2014) $\mathrm{W}_{0}$ estimates in the frame of the GGOS working group on vertical datum standardisation. In: Marti U (ed) Gravity, geoid and height systems, vol 141. IAG Symposia Series. Springer, Cham, pp 203-210. https://doi.org/10.1007/9783-319-10837-7_26
Sánchez L, Čunderlík R, Dayoub N, Mikula K, Minarechová Z, Šíma Z, Vatrt V, Vojtíšková M (2016) A conventional value for the geoid reference potential $\mathrm{W}_{0}$. J Geod 90(9):815-835

Schaeffer P, Pujol MI, Faugere Y, Picot N, Guillot A (2016) New Mean Sea Surface CNES_CLS 2015 focusing on the use of geodetic missions of CryoSat-2 and Jason-1. Presented at OSTST 2016 meeting, La Rochelle, France

Sjöberg LE (1977) On the errors of spherical harmonic developments of gravity at the surface of the earth. Rep Dept Geod Sci No. 257, OSU, Columbus, Ohio

Sjöberg LE (2007) The topographic bias by analytical continuation in physical geodesy. J Geod 81:345-350

Sjöberg LE (2013) New solutions for the geoid potential $\mathrm{W}_{0}$ and the Mean Earth Ellipsoid dimensions. JGS 3(2013):258-265

Sjöberg LE, Bagherbandi M (2017) Gravity inversion and integration. Springer, Berlin. https://doi.org/10.1007/978-3-319-50298-4

Stokes GG (1849) On the variation of gravity on the surface of the Earth. Trans Camb Philos Soc 8:672-695

Tapley BD, Bettadpur S, Watkins M, Reigber C (2004) The gravity recovery and climate experiment: mission overview and early results. Geophys Res Lett 31(9):1-4. https://doi.org/10.1029/ 2004GL019920

Torge W (1989) Gravimetry. Walter deGruyter, Berlin

Tscherning CC (1984) The Geodesist's handbook, resolutions of the International Association of Geodesy adopted at the XVIII General Assembly of the International Union of Geodesy and Geophysics, Hamburg 1983. Bull Géod 58:3

Wahr J, Molenaar M, Bryan F (1998) Time variability of the Earth's gravity field: hydrological and oceanic effects and their possible detection using GRACE. J Geophys Res 103:30205-30229

WCRP Global Sea Level Budget Group (2018) Global sea-level budget 1993-present. Earth Syst Sci Data 10(3):1551-1590. https://doi. org/10.5194/essd-10-1551-2018 